Portland State University

PDXScholar

\title{
Active and Public Transportation Connectivity between North Temple TOD and Jordan Park River Trail
}

Ivis Garcia Zambrana

University of Utah

Christie Oostema

University of Utah

Follow this and additional works at: https://pdxscholar.library.pdx.edu/trec_reports

Part of the Transportation Commons, and the Urban Studies and Planning Commons Let us know how access to this document benefits you.

\section{Recommended Citation}

Ivis Garcia Zambrana and Christie Oostema. 2017. Active and Public Transportation Connectivity between North Temple TOD and Jordan Park River Trail. NITC-RR-990. Portland, OR: Transportation Research and Education Center (TREC). https://doi.org/10.15760/trec.186

This Report is brought to you for free and open access. It has been accepted for inclusion in TREC Final Reports by an authorized administrator of PDXScholar. Please contact us if we can make this document more accessible: pdxscholar@pdx.edu. 


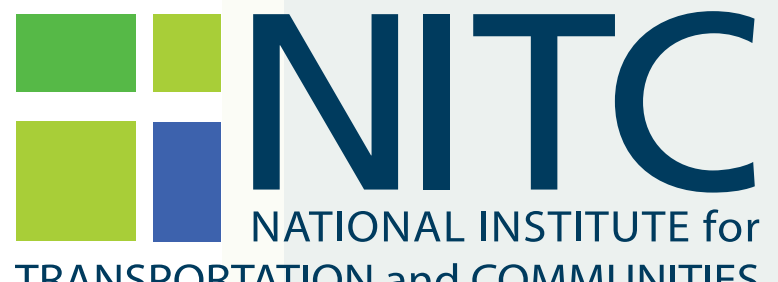

TRANSPORTATION and COMMUNITIES

FINAL REPORT

Active and Public Transportation Connectivity between North Temple TOD and Jordan Park River Trail

NITC-RR-990 $\quad$ October 2017

NITC is a U.S. Department of Transportation

national university transportation center.

HI! TREC 



\section{ACTIVE AND PUBLIC TRANSPORTATION CONNECTIVITY BETWEEN NORTH TEMPLE AND THE JORDAN RIVER PARKWAY TRAIL}

\section{FINAL REPORT}

NITC-RR-990

by

Ivis Garcia Zambrana (PI)

Westside Studio

University of Utah

for

National Institute for Transportation and Communities (NITC)

P.O. Box 751

Portland, OR 97207
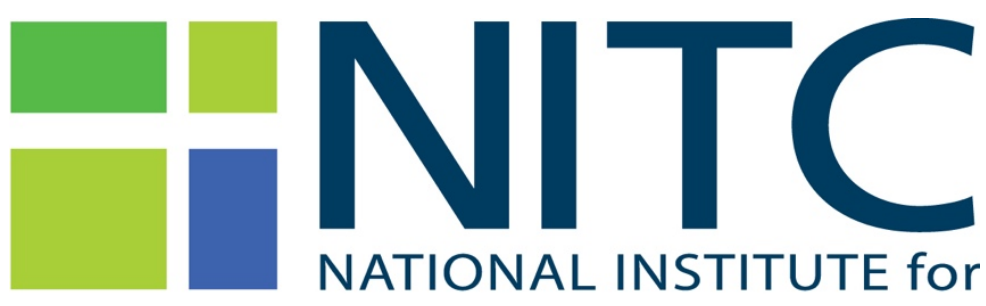

TRANSPORTATION and COMMUNITIES

October 2017 


Technical Report Documentation Page

\begin{tabular}{|c|c|c|}
\hline 1. Report No. NITC-RR-990 & 2. Government Accession No. & 3. Recipient’s Catalog No. \\
\hline \multirow{3}{*}{\multicolumn{2}{|c|}{$\begin{array}{l}\text { 4. Title and Subtitle } \\
\text { Active and Public Transportation Connectivity between North Temple TOD and Jordan } \\
\text { Park River Trail }\end{array}$}} & 5. Report Date \\
\hline & & October 2017 \\
\hline & & 6. Performing Organization Code \\
\hline \multicolumn{2}{|c|}{$\begin{array}{l}\text { 7. Author(s) } \\
\text { Ivis Garcia Zambrana and Westside Studio }\end{array}$} & $\begin{array}{l}\text { 8. Performing Organization Report } \\
\text { No. }\end{array}$ \\
\hline \multirow{2}{*}{\multicolumn{2}{|c|}{$\begin{array}{l}\text { 9. Performing Organization Name and Address } \\
\text { University of Utah, } 375 \text { South } 1530 \text { East, Salt Lake City, UT 84112-0370 (Room 235) }\end{array}$}} & 10. Work Unit No. (TRAIS) \\
\hline & & $\begin{array}{l}\text { 11. Contract or Grant No. } \\
\text { NITC-UU-12 }\end{array}$ \\
\hline \multirow{2}{*}{\multicolumn{2}{|c|}{$\begin{array}{l}\text { 12. Sponsoring Agency Name and Address } \\
\text { National Institute for Transportation and Communities (NITC) } \\
\text { P.O. Box } 751 \\
\text { Portland, Oregon } 97207\end{array}$}} & $\begin{array}{l}\text { 13. Type of Report and Period } \\
\text { Covered } \\
\text { Final Draft Report/ Jan.-Aug. } 2016\end{array}$ \\
\hline & & 14. Sponsoring Agency Code \\
\hline
\end{tabular}

16. Abstract

The project seeks to capitalize on existing community assets - several TOD stations and a regional bike and pedestrian trail system - by studying how these can be linked. The overarching goal of this project is to increase scholarship on networking safe routes that can encourage public and active transportation choices and thus, encourage a healthier lifestyle and advance sustainability. By expanding pedestrian, bicycle and transit connections to green space and offering the most potential for TOD, this proposal clearly demonstrates the greatest priorities of NITC. Moreover, nationwide, communities like Salt Lake's West Side are in greater need of sustainable transportation choices that foster livability because a high proportion of low-income and minority populations tend to be transit users and/or utilize active transportation facilities.

Historically, the West Side has been cut up and cut off from the rest of the city, first by several rail lines, later by two interstate freeways. The city's new light rail line through the neighborhood begins to stitch the city back together; the Jordan River Parkway, a regional bike/walk path, bisects the rail line and runs through the heart of West Side neighborhoods. This project explored the relationship of these two assets, as well as their significance to local resident use and access using quantitative tools like surveys, GIS mapping and socioeconomic analysis. We also began to understand how to improve neighborhood connections from a resident perspective, using qualitative data, as well as access to the rest of the city and to other West Side amenities via transit and active transportation. When a neighborhood receives regional-scale amenities, like major transit linking downtown and the airport and a regional trail spanning an entire valley, it is important that resident voices are heard, that local leadership gains a voice and that regional amenities become true neighborhood assets. We explored and documented community-engaged ways of learning from the neighborhood in order to improve equity, identify transportation goals and spark local action.

\begin{tabular}{l|l} 
17. Key Words & $\begin{array}{l}\text { 18. Distribution Statement } \\
\text { No restrictions. Copies available from NITC: } \\
\text { Active transportation, trails, transit oriented development }\end{array}$ \\
www.nitc.us
\end{tabular}

19. Security Classification (of this report)

Unclassified

20. Security Classification (of this
page)

Unclassified

\begin{tabular}{l|l} 
21. No. of Pages & \\
64 &
\end{tabular}

22. Price 



\section{ACKNOWLEDGEMENTS}

Westside Studio Students

Jordan Baker, Aaron Barlow, Tyler Cain, Kevin Cisney, John Close, Jeni Crookston, Christy Dahlberg, Annaka Egan, Brian Hoole, Christianna Johnson, Shabnam Sifat ara Khan, Isobel Lingenfelter, Steven Lizzarago, Lynn Lyons, Sharif Mahmud, Amber Mortensen, Xiaoyang Niu, Corinne Piazza, Sydney Rich, Jenna Simkins, Kathrine Skollingsberg.

Instructors

Ivis Garcia Zambrana, Christina Oostema Brown

Research and Teaching Assistants

Casey Walrath, Ian Kilpatrick, Megan Townsend

Writer

Shabnam Sifat Ara Khan (literature review, study objectives, and methods primarily)

Community Partners

University Neighborhood Partners, NeighborWorks Salt Lake, Access North Temple, Fairpark Community Council, Green Bike, Jordan River Commission National Park Service, Poplar Grove Community Council, Seven Canyon Trust, SLC Bike Collective and SLC Government

This project was funded by the National Institute for Transportation and Communities.

\section{DISCLAIMER}

The contents of this report reflect the views of the authors, who are solely responsible for the facts and the accuracy of the material and information presented herein. This document is disseminated under the sponsorship of the U.S. Department of Transportation University Transportation Centers Program in the interest of information exchange. The U.S. Government assumes no liability for the contents or use thereof. The contents do not necessarily reflect the official views of the U.S. Government. This report does not constitute a standard, specification, or regulation. 


\section{TABLE OF CONTENTS}

1.0 EXECUTIVE SUMMARY .......................................................................................... 1

1.1 KEY FINDINGS................................................................................................

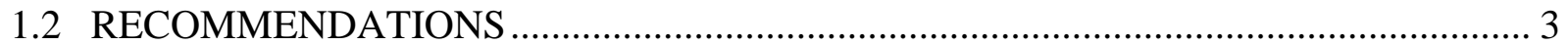

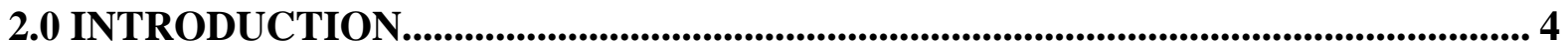

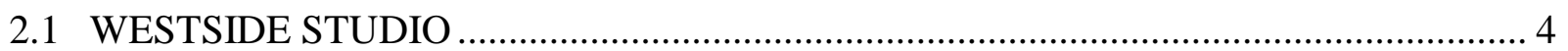

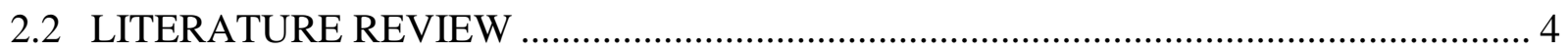

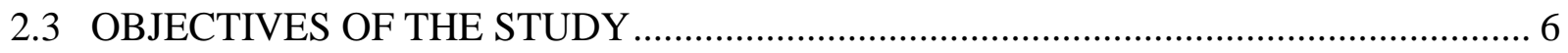

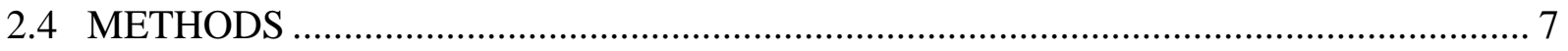

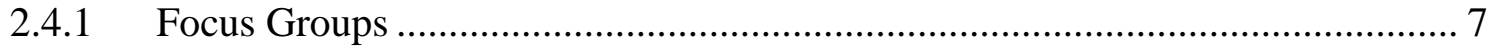

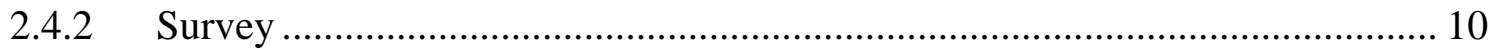

3.0 GETTING TO KNOW THE WESTSIDE............................................................. 12

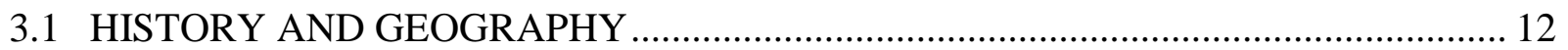

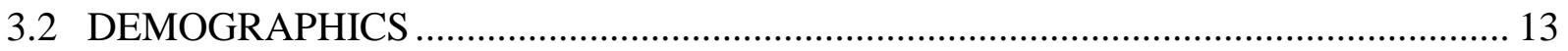

3.2.1 Race and Ethnicity …………........................................................................ 13

3.2.2 Housing and Income ....................................................................................... 13

3.2.3 Crime and Perceptions of the West Side.............................................................. 14

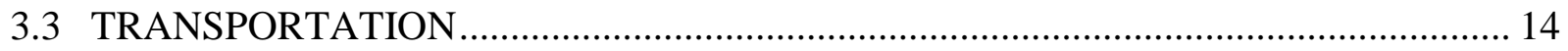

4.0 WESTSIDE ASSETS AND INFRASTRUCTURE........................................................ 15

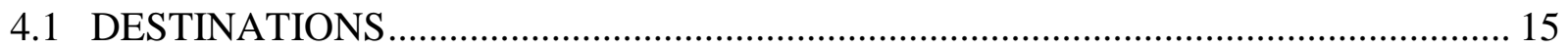

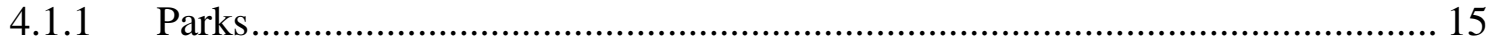

4.1.2 Libraries and Schools............................................................................... 15

4.2 TRANSPORTATION INFRASTRUCTURE ............................................................ 16

4.2.1 Bicycling Infrastructure ............................................................................. 16

4.2.2 Pedestrian Infrastructure ......................................................................... 16

4.2.3 Pedestrian Count Observations ......................................................................... 17

4.2.4 ADA Compliance and Safety ........................................................................... 17

4.3 SUMMARY OF BARRIERS TO ACTIVE TRANSPORTATION …………………...... 18

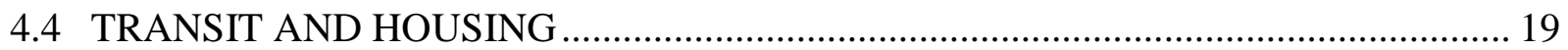

4.4.1 Transit Stations and Bus Stops .................................................................... 19

4.4.2 Housing Density.................................................................................... 20

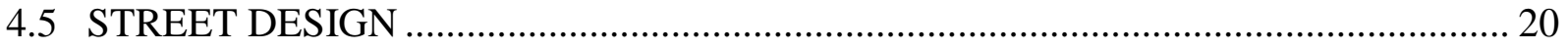




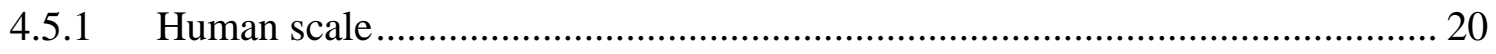

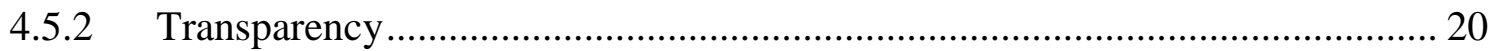

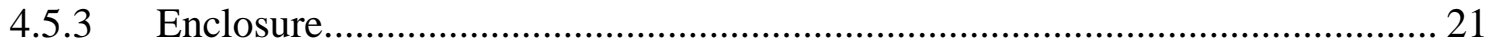

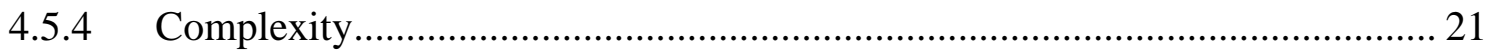

5.0 LEARNING FROM THE COMMUNITY .............................................................. 22

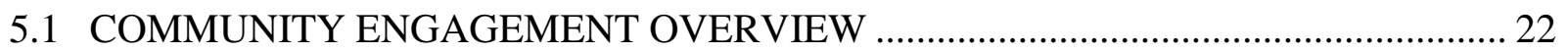

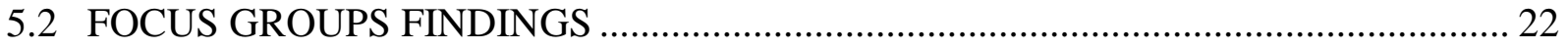

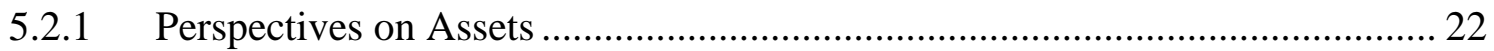

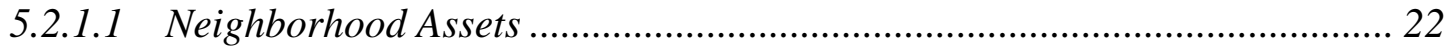

5.2.1.2 Jordan River Parkway Trail as an Assets................................................ 24

5.2.1.3 North Temple as an Asset ........................................................................ 25

5.2.2 Perceived Challenges and Opportunities ..................................................... 26

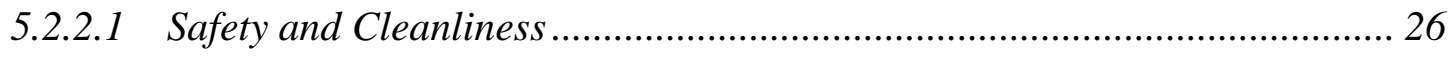

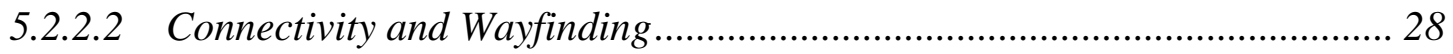

5.2.2.3 Pedestrian Engagement, Destinations and Events .................................... 30

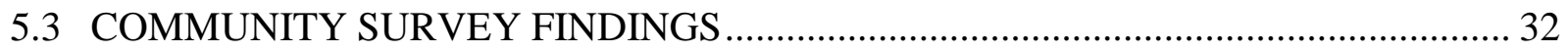

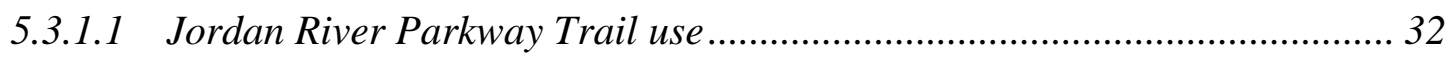

5.3.1.2 Modes of accessing the Jordan River Parkway Trail ................................. 33

5.3.1.3 Times of the day that respondents use the trail.......................................... 33

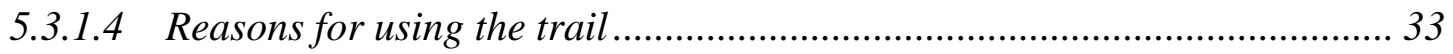

5.3.1.6 Significant impediments to using the trail ............................................ 33

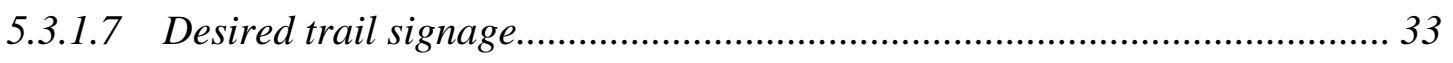

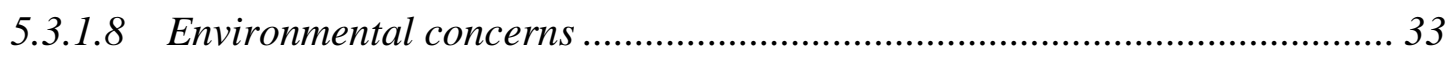

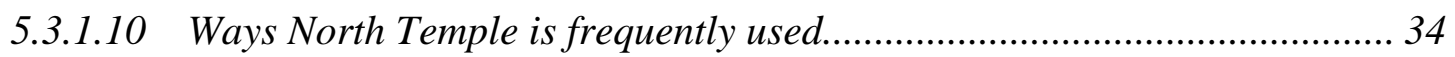

5.3.1.14 Ways to encourage walking, biking and transit on North Temple.............. 34

5.3.1.15 Types of improvements to encourage people to use active mode choices . 34

5.3.1.16 Barriers to walking or biking along North Temple .................................. 35

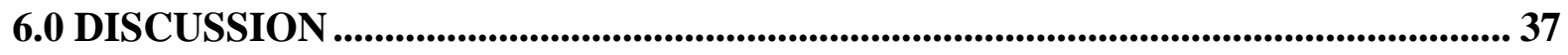

7.0 RECOMMENDATIONS........................................................................................ 38

7.1 BATHROOMS, WATER FOUNTAINS AND TRASH CANS .................................. 38

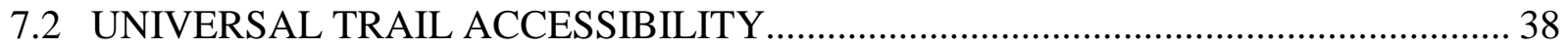

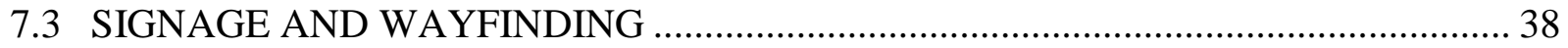




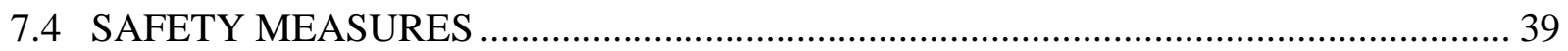

7.5 ENTERTAINMENT AND DESTINATIONS ………….............................................. 40

8.0 IMPLEMENTATION ......................................................................................................... 41

8.1 PROJECT IMPLEMENTATION PRIORITY TABLE …………………………........... 41

8.2 SIGNAGE AND WAYFINDING …………………................................................ 41

8.3 PEDESTRIAN ENGAGMENT AND PUBLIC ART ...................................................... 42

9.0 CONCLUSION ................................................................................................................. 44

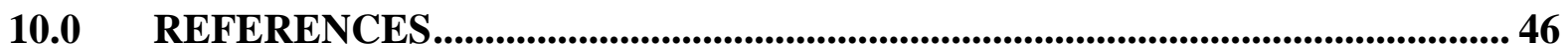

\section{LIST OF FIGURES AND TABLES}

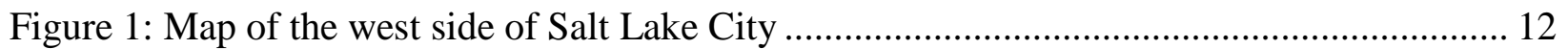

Figure 2: Barriers to walking along North Temple.................................................................... 18

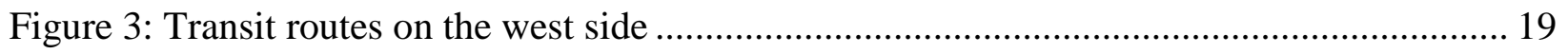

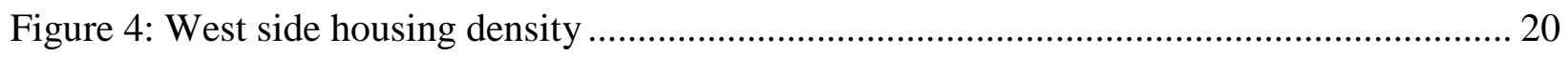

Table 1: Prioritized recommendations for policy and project implementation ............................. 41

Figure 5: Sign designed and installed by Westside Studio to raise awareness of destinations. ... 42

Figure 6: Mural on North Temple being restored by Westside Studio students and partners...... 43 



\subsection{EXECUTIVE SUMMARY}

Students in the University of Utah's Westside Studio researched and developed this project by studying the west side's history and demographics, conducting surveys and focus groups with residents and performing on-site analyses of infrastructure and amenities. This report explores active transportation connections between the Jordan River Parkway Trail and the North Temple corridor on the west side of Salt Lake City, Utah. Its purpose is to evaluate sidewalks, trails and transit and to document their connections to neighborhood assets. This information is then used to diagnose issues and propose improvements that will strengthen those connections to better promote active transportation methods like walking and bicycling.

The physical divide between the west side and east side of the city that has developed historically led the neighborhoods suffer from various stigma, negligence and economic downturns. It also affected their sense of community, with the media coverage focusing on crime activity and poverty. Concerns regarding the safety issues in the neighborhood were also evident from the suggestions the residents put forward. They were concern about traffic safety and crime in particular addressing the problem of homelessness in the area. They associated the reduction of criminal activities and undesirable land uses (like motels) from the area with improved environmental quality, a rise of local business activities and a sense of place.

Besides safety, another consideration emphasized that affects walking, biking and taking transit is connectivity. Residents found connectivity in the area to be somewhat incomplete in, particularly in the trail. Some avid and comfortable users of bike also reported that they did not bike on the Jordan River Parkway Trail due to the lack of connectivity. For example, "Coming from the 500 north areas to get to TRAX, there is no access from Redwood Road to 900 west. Really there is no easy way to get to public transportation from many parts of the Jordan River Parkway Trail. If you don't know where you're going, you'll have to walk the whole trail to figure out how to get off of it.” Residents felt that signage could help walkers and biker to find destinations outside of the trail like North Temple, where there is transit, restaurants and a number of amenities. Participant also said that signage could help people in the neighborhood to discover the trail. A residents commented, "Some of my neighbors do not even know that the Jordan River Parkway Trail exists.” They felt it was important to launch a public training on trail usage.

Regarding North Temple, there was discussion about the existing street furniture and landscaping not necessarily contributing to a comfortable bicycle and pedestrian environment, due to the area's lack of interests, large open spaces, lack of shade and enclosure. Survey results show that the majority of respondents (57\%) primarily access the North Temple corridor by automobile rather than public (19\%) active transportation options such as walking (13\%) and biking (8\%). Eating out in a restaurant and accessing the TRAX line appeared to be the most popular reasons for using the corridor among the participants. The percentages of people for these two purposes were found to be $27 \%$ and $23 \%$ respectively. The second sets of popular reasons were getting to work or school and shopping for groceries presenting $16 \%$ and $14 \%$ of 
the participants. Surprisingly, very few people used the corridor for recreation as represented by $3 \%$ of the respondents.

Both the Jordan River Parkway Trail and the North Temple Corridor are located in autoscaled street networks and oriented towards drive ways, few of which can be accessible via bus, as the alternative mode. Bike and walk trips could take a considerable amount of time. This suggests that the absence of reliable Pedestrian Street network and distance are barring the neighborhood from taking advantage of a strong community web that promotes social, environmental, and economic services to the residents of the area. Connecting the neighborhood with pedestrian oriented street grids and various alternative transportation routes is fundamental to an overall stronger setting for the growing population west side neighborhoods.

This report aimed to contribute to the literature on TOD by investigating the connections between TOD and trails nearby in low-income neighborhoods. While TOD investments have brought to low-income areas access to public transit, the lack of destinations and perceptions of public safety are still a challenge to attract people to TOD. The same problem was found in the trail, more destinations along the trail as well as more safety were identified as main concerns for users. Solving these two issues would perhaps increase the use of public transit and active transportation. In addition to these two issues, which have been identified in the literature already (but not in conjunction) as major barriers for alternative modes of transport, we identify the connectivity piece as important. We hope that our key findings and recommendations below are useful to other cities where low-income neighborhoods enjoy of TOD and trails within walking distance from each other.

\subsection{KEY FINDINGS}

- This study suggests TOD is transforming low-income neighborhoods in transit-rich areas. Nonetheless, other challenges related to economic development and the perception of crime persist. Encouraging the development of amenities and increasing security in low-income trail- and transit-rich neighborhoods would be important step to improving connectivity and increasing transit ridership, walking, and biking.

- The Jordan River Parkway Trail is a significant asset, but most residents do not use it. A total of $40 \%$ reported never being on the trail. Of those who do about one third drive to the area, even if the live less than a mile from it. About one third of those who bike use it to connect to other community destinations and avoid cars (as opposed to recreation), including North Temple.

- Unclear wayfinding and disconnected trail routes is one of the biggest challenges in the area where North Temple crosses the Jordan River Parkway Trail.

- North Temple has a tremendous potential, with easy access to transit, stretches of quality pedestrian and bicycle infrastructures and a number of amenities including a popular restaurant and coffee shop. Its primary challenges as a pedestrian space arise from its development as an automobile-oriented road-despite the fact that there is light rail and efforts to build Transit Oriented Development-with lots of parking lots and drive-through.

- Safety is a major concern for walkers at both the Jordan River Parkway Trail and the North Temple corridor. Some concerns related to traffic safety, while most concerns related to crime related to homelessness, prostitution and alcohol/drug addiction. 


\subsection{RECOMMENDATIONS}

- New transportation investments aiming to improve transit and active transportation should take into consideration the existence of other amenities in the neighborhood whose purpose is walking or biking e.g. trails, paths and so on. Moreover, trails and transit rich, but low-income neighborhoods need to pay more attention to safety concerns and the existence of amenities as well as connectivity between the two.

- Improve signage and wayfinding, especially at trail entrances and exits. Hence, there should be promotion of comprehensive signage and displays in the area highlighting the connection between the trail and the North Temple Corridor. Drivers, cyclists, public transportation users, and pedestrians in the neighborhood should all be made aware of the nearby amenities and their approximate distance away from each of these amenities.

- Take measures that improve perceptions of safety in the area, including trail lighting. As mentioned earlier, a common theme in both the user survey and the focus group area was the perception of being unsafe. Also, a majority associated darkness and the lack of lighting along the trail with the safety issues. In addition to increased lighting on the trail, the same is recommended along the North Temple Corridor.

- Encourage entertainment and events that use the trail and North Temple-incentivize those who arrive walking, biking or taking transit. As supported by the discussion, event-related transit accessibility options such as concerts, food trucks, beer gardens, outdoor movies, and festivals were some of such opportunities which could make the connectivity reunite.

- Add more bathrooms, water fountains and trash cans along the Jordan River Parkway Trail. Many residents noted that another barrier to enjoying the trail was the lack of restrooms and trash bins. Building restrooms and placing trash bins are also suggested to increase the number of users. It is hoped that with the awareness of the great community assets in the area and their ease of access, residents will feel a greater sense of community.

- New transportation investments aiming to improve transit and active transportation should take into consideration the existence of other amenities in the neighborhood whose purpose is walking or biking e.g. trails, paths and so on. Moreover, trails and transit rich, but low in-income neighborhoods need to pay more attention to safety concerns and the existence of amenities. 


\subsection{INTRODUCTION}

\subsection{WESTSIDE STUDIO}

This report and the research contributing to it was produced by Westside Studio, a workshop course offered by the University of Utah through its Department of City and Metropolitan Planning. For Spring 2016, the course studied active and public transportation connectivity between North Temple and the Jordan River Parkway Trail. The project goal is to better connect Salt Lake City's west side neighborhood with planning efforts by mapping assets, identifying needs, partnering with neighborhood groups and developing projects for implementation. This document presents the studio's research and recommendations for promoting active and alternative modes of transportation, especially walking, cycling and public transit.

The North Temple/Jordan River Parkway Trail connection is an important location to study because it is the junction of one of the city's major arterial roads and its longest public trail. In addition, the area has transit access via TRAX light rail and bus routes and offers connections with a number of regional bicycle and pedestrian paths. The hope is that focusing on active transportation connectivity can ultimately encourage greater equity and justice for the west side, which has historically received less attention than other parts of Salt Lake City. This report may be a useful building block for future collaboration between planners and neighborhood organizations.

\subsection{LITERATURE REVIEW}

The role of the built environment in facilitating active transportation in a neighborhood has garnered a considerable attention in the planning realm (Frank et al. 2007, Saelens et al. 2003 and Ewing and Cervero, 2001). Through their seminal research, Cervero and Kockelman (1997) and Frank and Pivo (1994) brought evidence into the relationships between accessibility and connectivity found in compact neighborhoods, resulting in higher walk trips than sprawling neighborhoods. Accessibility refers to pedestrian facilities as well as destinations such as stores, transit stops and so on. Street connectivity is defined as how street networks align to create a direct route for users. A sound street connectivity often suggests providing alternative routes between the origin of trips and destinations. Connectivity has been described mostly by intersection density, average block length and straight line distances between trip origin and destination (Handy 1996, Hess 1997, Handy et al. 2002).

Ewing and Cervero (2010) identified urban design qualities that influence walkability - that is, the "5Ds," density, diversity, design, distance to transit and distance to opportunities. Corroborating these findings, public health research shows how such physical and environmental factors can influence behavioral patterns related to health, especially with regards to mode choice and active transportation (Salmon et al. 2003, Bargh and Ferguson 2000, Bargh and Chartrand, 1999, Sallis et al. 1999). Examining how environmental attributes influence physical activity in general, Sallis and Owen (2002) showed that factors such as aesthetics, convenience and access resulted in higher active travel levels. Framing the context from an urban planning research perspective, Saelens et al. (2003) employed the aforementioned factors to show how they impacted biking and walking as utilitarian mode choices. 
Sallis et al. (1990) argued that greater accessibility resulted in higher levels of participation in active transportation regardless of socioeconomic status. In other words, low income individuals living in accessible neighborhoods engaged in active transportation at the same rate than their wealthier counter parts. Other studies have found that after controlling for access to a personal vehicle, socioeconomically disadvantaged neighborhoods in general have poor walking accessibility and thus, these areas had lower numbers of people participating in active transportation (Macintyre et al. 1993, King et al. 1995).

Active living research has also taken into consideration safety, both perceived and actual, impacting walking behavior. Empirical findings from Joh et al. (2012), Mason et al. (2013) and Handy (2006) support that walking behavior is related to safety-being crime or car accidents. Moreover, Wood et al. (2008) and Loukaitou-Sideris (2006) showed that some land uses such as liquor stores and motels could discourage walking while improving lighting or mixed use developments encourage walkability. Mixed land uses and lighting facing the street reduced walkers' fears who felt that corridors had more community surveillance or "eyes on the street." Tracing the linkage between these aforementioned factors Hong and Chen (2014) quantified the connections among the built environment, perceived notions of safety and walking behavior. In their study they found that people living in safe and accessible areas are more likely to walk. However, they reported that density could also have a negative effect in the perception of safety if there is crime in the area.

Literature shows adequate examples of how good design in the built and physical environment relates to quality of life (Hedman and Jaszewski 1984, Low and Smith 2006, Mitchell 2003). Reviewing urban space literature from the past 40 years and presenting empirical data using Kuala Lumpur as a case study, Mahmoudi et al. (2014) showed that livability is affected by physical attributes which is in turn influenced by place quality. Place quality is interpreted from various dimensions - it is the sensorial experience that a place provides to its residence as a combination of social, physical, environmental and economic features that may change over time (Kloosterman and Trip 2011).

The functionality of a place highly influences quality of life. This component refers to the usefulness of places in surrounding land uses (Southworth 2005) and the resources and services it offers to sustain life (Mehta 2008). Functional places might include cafes, restaurants, cultural facilities etc. that serve the daily needs of people. A functional place might also consist of the natural environment that might include but are not limited to enjoyment of open spaces (El Din et al. 2012). In addition, functional places might create employment opportunities and support economic growth (Kloosterman and Trip 2011). Outside of preserving and enhancing natural areas, creating functional places, requires considerable economic investment in the built environment (Myers 1988, Rowley 1998). Mixed land uses are another important element. In order to provide access to functional places like cafes, restaurants, etc. planning divisions would need to create the appropriate zoning for encouraging the mix of uses. Both the abovementioned functional and mixed uses lay the framework for residents to engage with the environment and with each other physically and emotionally. It creates the cultural and intellectual conditions where residents can thrive by promoting social integration and social participation (El Din et al. 2012).

Thus, pleasurability reflects the social, economic and safety dimensions of quality of life. All these factors finally generate an array of interlocking features that influence the overall quality of 
life which refers to personal satisfaction with residential characteristics - transportation, housing, schools, parks, etc. Hence, Myer (1988) regards quality of life to be a shared characteristic that residents in a community experience and their subjective evaluations of these conditions. According to Myer, planners should engage in comprehensive planning and take a holistic view of places using quality of life as a framework, as opposed to divide the field in housing, economic development, transportation and so on. In order to achieve a better quality of life, he argues, we need to stop working in silos.

Often regarded interchangeably with quality of life, the place quality has been explored from various dimensions. For example, McCrea et al. (2005) investigated quality of life and the subjective evaluations of it at a different spatial level. He found regional services such as access to health and higher education services gained the highest satisfaction at a regional level while neighborhood satisfaction was found to be associated with social interactions, crime and urban amenities such as K-12 schools, parks and libraries. At the finest level, satisfaction was based on quality of the house or apartment. Corroborating their research Lora et al. (2010) showed that individual's quality of life was a factor of people valuing and using amenities and services provided in their city and vicinity or neighborhood surrounding their home.

Identifying how neighborhood improvements impact residents' quality of life is impossible without finding out what people value and care highly about in their neighborhood (Myers 1988). General tools that planners deem to be most useful to encourage active transportation may not necessarily be what is needed in every neighborhood. It is important to consider culture, social contexts, spatial attributes and the built environment together to see how they affect travel behavior (Sauter and Huettenmoser 2008). Thus, the objective of this study is to assess the effectiveness of built environment factors, connections between the Jordan River Parkway Trail and the North Temple corridor in particular, in offering quality of life to a low income neighborhood and encouraging active and public transportation. The key focus is connectivity between these two neighborhood amenities.

\subsection{OBJECTIVES OF THE STUDY}

The relationship between land use and perceptions of walkability has been well studied in planning literature in terms of urban design, economic development and so on. The rise of transit oriented development (TOD) as a set of designs and policies centered around transit hubs has likewise gained importance in both academic study and professional practice. One topic that has received less study, however, is on the intersection of TOD and trails, and how that can affect the perception of both for pedestrians and residents nearby. Salt Lake City, Utah, presents a unique opportunity for such a case study at the point where the Jordan River Parkway Trail, a public trail running along the city's largest river, meets its TRAX light rail system.

In conceptualizing how the build environment affects user perceptions in an environment that incorporates both transit and trails, it's important to determine which aspects of the experience is being measured. This includes understanding the function of each-if the trail's primary purpose is aesthetic, it may not attract pedestrians who tend to value route directness over aesthetics in the built environment (Agrawal et al. 2008), although access to green and natural spaces is an important component of walkability as a leisure activity (Montemurro et al. 2011). In addition, demographics and socioeconomic factors must be considered, because even disadvantaged areas that score high in highly walkable areas tend to have lower perceived walkability (Jun et al. 
2015). Areas with lower socioeconomic status tend to have less public investment in infrastructure and destinations that encourage walking (Yildrim 2012).

Finally, there is the question of the extent to which traditional qualitative predictors of perceived walkability may be impacted by the presence of trails or open space. Research has indicated that active street frontage and high amounts of visual transparency are important indicators of walkability (Ewing et al. 2016), but such measures tend not to consider the possibility of a trailhead nearby. Location matters, especially for transit stops or trails near major arterials, which people tend to view as unattractive and inimical to walking (Adkins 2012). It is also important to look at a site holistically as part of the city's broader walking network and consider which destinations are served from the site (Alfonso 2005).

Given this gap in the literature, the objective of this project-outside of this particular geography-is to help policy makers understand how some aspects of the built environment can limit or enhance the use of alternative modes of transportation to and from TOD and trails. Thus, the main question that this research seeks to answer is: How can planners best create a pedestrian, bike, and public transportation network to and from TOD station areas and a regional trail system? The objectives of this project will be achieved by: first, analyze existing conditions to perform a gap-analysis and second, analyze how to connect the gaps between North Temple TOD and the Jordan River Park Trail. A mixed-method approach was employed-including observations, surveys and focus groups - to understand how these two spaces are currently linked, what the gaps are, and how can they be bridged. These methods are discussed in the next section.

\subsection{METHODS}

Research conducted by Westside Studio focused on the impact and use of neighborhood assets, using tools like community outreach, data analysis from geographic information systems (GIS) maps and the United States Census and qualitative onsite analysis. An asset based approach is important because it frames planning efforts in positive terms, focusing on what already works rather than what an area lacks. This promotes greater neighborhood ownership and agency, rather than top down instruction.

Community outreach via surveys and focus groups were a key aspect of the project, allowing Westside Studio to gather in depth information from people living in the area. Their local knowledge was critical for understanding local social, environmental and economic issues. Surveys were also distributed to hundreds of residents to gather broad data on how residents use neighborhood assets and what elements they would like to see improved.

\subsubsection{Focus Groups}

A focus group is a research technique in where questions are asked in a group setting on a targeted issue. Generally, the group is composed of anyone with a vested interest in the topic and they might represent different subject positions (e.g. Latinos, women, young people, residents, community leaders, etc.). The usual setting looks like a small community gathering that feels friendly for discussion and allows communication among all participants-without someone dominating the conversation. The facilitator should value what people say and consider them experts on the matter (Skop 2006, Hemingway et al. 2012). A facilitator usually uses a focus 
group protocol to systematically move the dialogue from problem identification to problem solving and/or from one topic to another. The idea is to gather as many points of view as possible to get a deeper understanding of the issue at hand, problems and/or potential solutions from a sociological perspective. A group conversation if different from an individual conversation and/ or interview in the sense that people can share and build knowledge together, what someone say might be elaborated by someone else and so on.

This research technique opens up a data collection framework where a facilitator could tweak and navigate the discussion in a more flexible manner than when using a survey. This is because while a survey holds a set of close ended questions and answers, a focus group discussion can avoid this rigidity by using semi structured questions. This means that the facilitator can navigate the discussion based in the group interest and participant's knowledge of a topic (Scott 2011). Moreover, facilitators can assess the weight of an issue depending on what people want to spend time discussing, what is relevant to them. The nuance of the focus group setting comes in the form of the participants' behavior, facial expressions and voice intonation can add a lot to understanding he importance of an issue (Morgan 1996). Conducting multiple focus groups also means that a facilitator can, based on their new knowledge and deeper understanding gained through focus group participants, fine tune their questions in between other focus groups to refine any given narrative as much as possible (Briggs 1998).

Focus group methodology provides participants an opportunity to share and gain knowledge; therefore, it builds and strengthens community trusts and capacity in the long run (Gaber 2007). Dialogue in a focus group setting can foster participatory democracy and therefore, it has the capacity of influencing decision-making. In the planning field, focus groups or small group discussions has its roots in collaborative communicative planning (Innes and Booher 2010, Healey 1997). While Flyvberg (2002) suggests that planners should include stakeholders in the decision making process so decisions are widely supported, Innes and Booher (2015) suggest that including diverse stakeholders will create the conditions necessary for a legitimate planning process, where the values and interests of those involved are represented. Through bringing as many people to the table whose interests are at stake, facilitators in group discussions can help balance power that would otherwise prevail if left unchecked. This form of research comes from the epistemological conviction that if the public is viewed as the source of power, then public input is necessary for power to be exercised (Friedmann 1998).

A total of five focus groups were conducted and included between three and nine participants per session. The focus groups were organized by Westside Studio students, faculty members and neighborhood partners between March 8th and March 16th of 2016. Participants came from a variety of ethnic/racial backgrounds and socioeconomic groups. The age range for the participants varied between 18 and 55, which also represented an approximate 40\% Hispanic and Latino background - which was representative of demographics in the area. In order to be more inclusive of Latino voices, one focus group conducted specifically for Spanish language speakers. The participants represented a diverse variety of backgrounds and knowledge. A variety of subject positions were represented including bikers, transit users, walkers, renters and homeowners. Participants represented a number of professional backgrounds and educational levels such as real estate developers, legal service holders, students, non-profit organizations staff, construction workers, business owners, public land management employees, to mention a few. The group brought together 32 participants who were urban planning professionals that 
worked/live in the area, community leaders elected to boards and commissions and west side residents across the neighborhoods of Glendale, Fairpark and Poplar Grove.

All of the focus groups were conducted in places frequented by community members such as coffeehouses, recreational centers and non-profit organizations. The place was carefully chosen to ensure accessibility using active and public transportation. All the focus group meetings served refreshments for the participants as a way to attract them to the meeting as well as fostering engagement. Focus groups were recorded, transcribed, translated, coded and analyzed to find patterns and trends of issues (Kitzinger 1994, Gaber 2007). Discussion focused primarily on three areas: (1) walkability and bikeability along North Temple, (2) uses of the Jordan River Parkway Trail and, (3) Connectivity between the two and ways to improve it. Questions included:

- What are some of your favorite places in the neighborhood?

- What places on the Jordan River Parkway Trail and North Temple do you go to?

- Do you bike or walk to these destinations?

- What do you feel makes the area bikeable or walkable?

- What do you think would prompt more people to walk or bike to North Temple or the trail?

- How do you and your friends and family use the Jordan River Parkway Trail and North Temple?

- What types of services or activities would encourage you to walk and bike more in these two areas?

These and other questions were created in conversations between a community leaders and the students. To carefully address the research questions, we held meetings beforehand to go over the issues to be discussed and based on which 10 research questions were formulated for each group. Each focus group was started with an ice-breaker question to make people feel comfortable and was followed by multiple open ended questions. The discussion was designed to have a combination of follow up and solely new questions which enabled a dynamic conversation. The focus group guide was standardized so it will be easy to by follow by moderators, but they were also told to be flexible if needed.

Community leaders were recruited by University Neighborhood Partners (UNP), an organization that is part of the University of Utah but is located in the Westside of Salt Lake City. Their mission is to create pathways to higher education and to connect faculty members and students with projects and initiatives in the west side. UNP trains indigenous leaders and connects them with faculty members and students. These community leaders attended class and mentor students. Community leaders were also in charge of recruiting participants as they knew people in the community and students did not. Students assisted with the preparation of flyers and recruitment materials. Participants were reached out via social media through the community's Facebook page, putting up announcement in the bulletin boards, emailing community contacts, in-person announcement with a sign-up sheet at community council meetings and personal invitation to friends. Although over 350 people were reached out, the response was less than $1 \%$.

Many of these leaders invited people who they thought were important stakeholders in their community (other community leaders who represented groups and/ organizations) as well as their neighbors and other people they knew in the community, but were not necessarily in 
leadership positions. The community leaders acted as facilitators of the discussion, since they knew every person who attended this helped us ensure that every participant has a chance to contribute, as they were not intimidated by a stranger. Students recorded and took notes at these meetings and assisted facilitators by bringing research materials, clarifying if there were any questions, buying and setting up the food and so on. Analysis was conducted by students. They presented preliminary focus group research to their community leaders and based on their feedback and understanding, the edited those findings. After the focus groups, community leaders visited class several times to comments on students' various iterations. Community leaders spend about 10-15 hours with the students. Community leaders were paid \$75 dollars at the end of the course as a way for us to say thank you for their time and services. UNP matching funds were used for these purposes. This is a long standing tradition of UNP as they think opportunities like this are important for the continuous development of community leadership. Without community leaders, this research would have missed local expertise, so we are thankful for their involvement.

\subsubsection{Survey}

For this study, the data were collected during the spring break between March 9th and March 16th of 2016 as part of the user survey assignment for the Undergraduate and Graduate Workshop class at the University of Utah. A convenient sample of 292 users out of about 19,000 adults who potentially could fill out the survey was taken, which is about $1.6 \%$ of the potential participants. The study area which borders the Rose Park, Fairpark and Poplar Grove from Interstate 15 to Redwood Road, and 900 South to 600 North (figure 1). Students used a face-toface method to collect these surveys and they offer as an incentive a pin that said, "I 'heart' west Salt Lake.” Students went to the transit stations, community centers and super makers. These locations were strategically chosen beforehand to reach out to as much variety as possible in the respondents in terms of age, race, gender, and user groups.

The survey was aimed at generating a guide that would assess how west side residents feel about their neighborhood in general. In order to do that, the survey was centered around information on the three main themes which are- the North Temple corridor, the Jordan Reivers

Parkway Train and connectivity issues. The survey consisted of 23 questions that asked about the users' experiences and feelings about these community assess. The initial idea for questions came from a stakeholder meeting with the Jordan River Commission, the Utah Transportation Authority, University Neighborhood Partners, NeighborWorks and several community councils. Students took these initial ideas and formulated a number of questions, totaling about 150 potential questions. A group of students then narrowed those questions to 20, which they shared with community partners. Community partners further refined the questions and went back and forward with the team of students in charge of producing a final survey draft. We wanted to collect data that would be useful to community partners as they were going to use the data for their own planning purposes.

Attitudes toward the quality of the neighborhood were measured by the frequency of their usage of the Jordan River Parkway Trail and the North Temple corridor, the key assets of the west side neighborhoods. To identify if the frequency was related to the proximity of where they lived, the survey also inquired about the distance of the trail from their houses and how they accessed the trail. To unfold more on their assessment of their neighborhood, additional 
questions were asked under this theme were what are their favorite things to do in the trail and why they use the trail. Both the latter questions provided a range of activities common for an urban river trail along with space where the respondents could write additional comments. For instance, the favorite activities along the trail options provided include walking, biking, running, dog walking, wildlife/nature watching and so on. As a way to find out about their attachment to the asset, the survey asked the types of improvements they would like to see in the trail in order to walk/bike more. For this question, the answer included almost all sorts of facilities starting from basics such as bathrooms, water fountains, and trashcans through more ambitious ones such as landscaping improvements. A blank space for additional comments was included as well. The final question specific to this theme asked was what the neighbors liked the most about the trail in relation to their neighborhood.

To understand the neighborhood perceptions on TOD as an asset, the survey focuses on the North Temple corridor since it is where TRAX is located, business, housing and streetscape improvements. Since it is a transit corridor, the attention is more towards the mode split, mixed uses and street improvements. Accordingly, the survey asked questions around the same focus which emerge with the third theme, the connectivity of the area. The questions include the destination choices served by the corridor, how they access the corridor, challenges that may occur in biking or walking in the corridor and the frequency of the transit usage for external trips. To find what could make the ridership rise, the respondents were asked to choose range of options such as the closer proximity of the stops, reliable destination accessibility, cheaper fares, and so forth. To tie this theme back to the community asset- the Jordan River trail in response to the streetscape improvements, people were asked about signage. From stakeholders and community leaders, signage was found to be an issue in the area. Therefore, the survey paid a considerable attention to it by inquiring about specifics which are what people like to see on the signs that are along the trail and the corridor and how they like to receive information about the trail. 


\subsection{GETTING TO KNOW THE WESTSIDE}

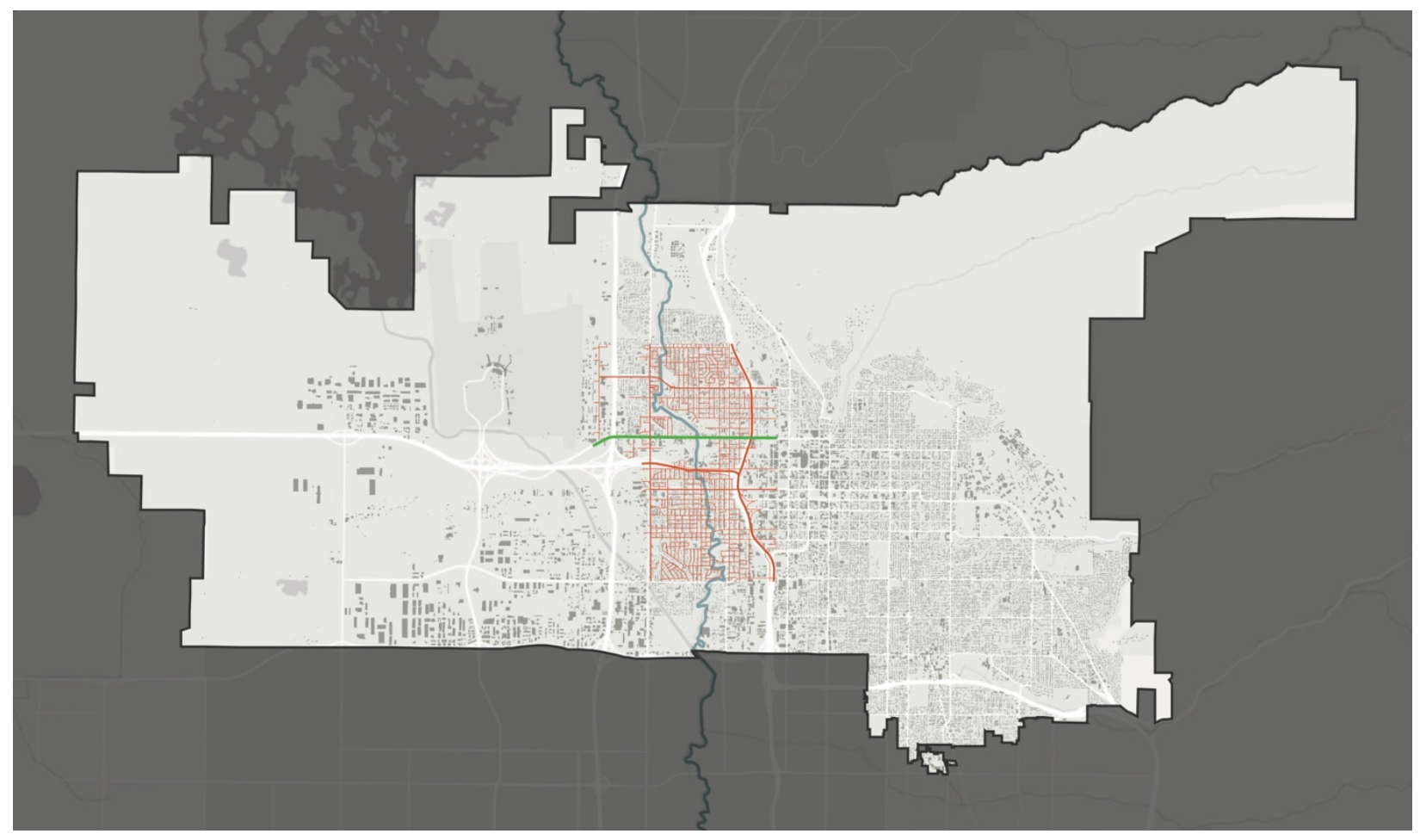

Figure 1: Map of the west side of Salt Lake City

\subsection{HISTORY AND GEOGRAPHY}

Salt Lake City's west side was settled by people of European descent since the arrival of Mormon pioneers in 1847. The area was planned as part of Salt Lake City's original grid and over time it developed into a distinct neighborhood as waves of immigration brought new residents and demographic shifts, with increasing urbanization throughout the $19^{\text {th }}$ and $20^{\text {th }}$ centuries.

Connectivity between east and west Salt Lake has historically been weak, with the eastern half of the city, which includes downtown and most of the city's government and religious buildings, typically receiving more attention. The transcontinental railroad formalized the east/west split in the late 1800s as rail yards and industrial areas dominated the dividing line and the streetcar network that crisscrossed the valley in the early $20^{\text {th }}$ century was sparse on the west side ("Railroads in Utah" 2016).

The mid-20 $0^{\text {th }}$ century rise of the automobile and the postwar highway boom further transformed the geography of the Salt Lake Valley. Interstate was build north-south along the railroad lines. Then, Interstate 80, running east-west and Interstate 215, a belt route, left much of the west side enclosed by freeways in a way that still severely limits accessibility for non-auto users. 
The Jordan River, which connects the Great Salt Lake to Utah Lake in the south, has always been one of the city's greatest assets. Running directly through the center of the west side, it has provided water and irrigation to residents for as long as the area has been settled. The river has also been used as a dumping ground for sewage and waste, which often created unsanitary conditions for people living near its banks. In 1973 the state legislature decided to address river pollution by creating the Provo Jordan River Parkway Authority, which was charged with enhancing the natural beauty of the river and improving its ecosystem and water quality. (Hallaran 2016).

The authority also helped to plan and develop a paved trail system that now connects 40 continuous miles of trails in Utah, Salt Lake and Davis County. The expansion of TRAX light rail to the west side in 2011, along with a number of recent streetscape improvements, a burgeoning local art scene and some new retail growth, have helped to begin reconnecting the west side with the rest of the city and to create more destinations in west side neighborhoods. The connection between the Jordan River Parkway Trail and North Temple, however, has remained largely the same for years. This report focuses on that intersection and its relationship to the broader west side community.

\subsection{DEMOGRAPHICS}

The demographic profile of the west side shows an area with a number of young families, many of whom are Spanish speaking Latinos. Understanding this can help planners emphasize improvements that benefit families and children, along with unique cultural offerings. Embracing universal design principles that benefit all kinds of users can be part of this process, along with developing plans that serve local residents and draw in visitors from elsewhere.

\subsubsection{Race and Ethnicity}

According to the 2014 US Census American Community Survey, the population of the census tracts surrounding the Jordan River Parkway Trail/North Temple intersection is about 32,000. Nearly two thirds that population is younger than 34 and about $30 \%$ under 17 . The area, like much of the west side, has a large Latino population, with over half of the population identifying as Hispanic or Latino and $40 \%$ as nonwhite, compared to $13.3 \%$ Latino and $13.8 \%$ nonwhite for Salt Lake County. About 30\% of residents were born outside the country and 24\% are not U.S. citizens. Over half residents speak a language other than English in their home, with Spanish being the most common second language. There are also smaller minority populations of Asian and Pacific Islander descent.

\subsubsection{Housing and Income}

Median household incomes for all west side neighborhoods are about \$41,000 according to American Community Survey data collected from 2009-2013, compared to $\$ 60,500$ for the county over the same period. One quarter of households are below poverty levels and half of that number include married couples with children. Unemployment is $12 \%$, higher than the $7.6 \%$ county rate.

Affordable housing and low rents have helped make the west side a destination for low income residents and immigrants. Median home values are around \$135,000, compared to 
comparable houses on the east side that are typically double or triple the price $(\$ 235,271$ was the 2014 county average). According to Census data the majority of housing units in the area are owner occupied, with low vacancy rates.

\subsubsection{Crime and Perceptions of the West Side}

Based on anecdotal experience discussed in focus groups and from Westside Studio students, some residents who live outside the west side have a negative perception of the area, or believe it to be less safe than the rest of the city. In fact, according to Crime Map produced by the Salt Lake City Police Department, the western North Temple area had fewer reported incidents than many other parts of the city, including downtown. A general lack of familiarity with the west side contributes to some misunderstandings, which is why improving connectivity and promoting west side destinations can help dispel negative stereotypes.

\subsection{TRANSPORTATION}

The west side near North Temple and the Jordan River Parkway Trail is part of an urban grid that includes residential neighborhoods with greater density than many newer suburbs, including mixes of single family homes, apartments and multifamily homes. North Temple itself is lined with fairly low density commercial and light industrial businesses, including hotels, restaurants and small factories. All of this makes public transportation a challenge, because effective transit requires certain densities of people or destinations. Although TRAX light rail and a number of bus routes provide service for most of the west side, most residents currently depend on automobiles. Planning efforts for active transportation should focus on individuals who can't or don't use automobiles, or who could be enticed to use different modes of transportation in the right circumstances.

For census blocks along the North Temple corridor, the highest rate of public transport use for work commutes over 2009-2013 was about 14\%, with other tracts having lower numbers. Altogether about $67 \%$ of residents commute alone in their own cars. More than half of workers live between 10 and 19 minutes from work, which means that efforts to promote active transportation could encourage a good number of workers to use alternative modes (Mattson et. al. 2014). 


\subsection{WESTSIDE ASSETS AND INFRASTRUCTURE}

\subsection{DESTINATIONS}

\subsubsection{Parks}

The west side has several excellent parks, including some along the Jordan River Parkway Trail and it's helpful to categorize and catalog these parks and their amenities when considering future plans for the area. At 1300 West 300 North is Constitution Park, which contains playgrounds, sports fields and is adjacent to recreation, senior and community centers. The park runs along the trail just north of North Temple and is accessible from the Fairpark TRAX station and several bus routes.

Further north along the trail to is Cottonwood Park at 1580 West 300 North. It includes a dog park and, like Constitution Park, offers limited public parking while still being transit accessible. Other parks in the area include the Rose Park Tot Lot and Post Street Tot Lot, smaller parks designed for children. These are located, respectively, about a mile north and south of North Temple within a few blocks of the river. Jordan Park, about a mile and a half south of North Temple, is also immediately adjacent to the trail.

Immediately east of Constitution Park, a block north of North Temple, is the Utah State Fairpark, which hosts events throughout the year, including expositions, auctions, rodeos and the annual Utah State Fair, which draws tens of thousands of visitors every year. Unfortunately, the Fairpark is fenced off except for select events, which can make it a barrier for accessing nearby areas. Also near the Fairpark grounds is the Fairpark Community Garden.

These parks and public spaces are important for bringing residents together and drawing visitors and should be a focus for any plans that involve active transportation connectivity. Emphasizing the parks as a unified system can help people see the neighborhood as a connected whole, which encourages exploration and a sense of community ownership.

\subsubsection{Libraries and Schools}

Libraries and Schools can be valuable assets and public gathering places and are especially valuable for disseminating information to the community. There are several libraries within one or two miles of North Temple, including the Day Riverside branch at 1575 West 1000 North, the Marmalade Branch at 280 West 500 North, the Chapman Branch at 900 West 577 and the downtown library at 210 East 400 South.

There are ten schools within the same area, all but one of which are elementary schools. The nearest high school is West High School, which is east of the freeway. Every school is accessible by walking to some degree and each has a Student Neighborhood Access Program (SNAP), which maps the safest routes to school for students, including locations of crosswalks, signalized intersections and good sidewalks. The schools are mostly located in residential neighborhoods and several are near the Jordan River Parkway Trail. Any improvements or changes in areas near schools should be further studied to ensure that safety and access remain priorities. Meanwhile, 
schools are excellent locations for distributing information and holding public meetings with proper notice and school district cooperation.

\subsection{TRANSPORTATION INFRASTRUCTURE}

\subsubsection{Bicycling Infrastructure}

Bicycle infrastructure plays a critical role in who chooses to bike and how often they do so. While a minority of cyclists will ride even without robust infrastructure, up to $60 \%$ of people are willing but hesitant to ride because of safety and other concerns. In order to address this group, cities have implemented solutions like dedicated bicycle lanes and signage to encourage cycling. A study by the National Institute of Transportation and Communities (NITC) found that adding a protected bike lane, in which riders are separated from auto traffic by parking and physical barriers, can increase bicycle traffic by up to 75\% in a year (Monsere et. al. 2014).

The Salt Lake City Pocket Bicycle Law states that bicycles cannot ride on sidewalks within certain parts of downtown and best practices in transportation planning generally recommend keeping bikes separate from pedestrians, with lanes at least four feet wide. Sidewalks, meanwhile, should be at least three feet wide. However, even with bike lanes some riders still ride on sidewalks regardless of regulations. In many instances, it makes sense to accommodate both riders and pedestrians with wide sidewalks at least seven feet across (eight feed might be most practical because it matches the standard length of lumber used for concrete forms, which can save costs while providing an extra foot).

North Temple has standard, unprotected bike lanes along each shoulder for most of its length. In Salt Lake City's bike map, this is sufficient to qualify North Temple as "high comfort," defined as a road with physical separation from autos or low traffic speeds (Emond, Tang and Handy 2009). However, because traffic speeds are fairly high, the unprotected lanes may deter some riders from using them. The Jordan River Parkway Trail, meanwhile, is classified as an off road trail and is generally safe and comfortable for bike riders. Bike infrastructure elsewhere is variable, with several nearby roads classified as "medium comfort," roads with painted bike lanes and high traffic (ibid). The nearest protected bike lane runs along 200 West, which intersects North Temple east of the freeway. While, 300 South is also protected for part its length on the east side.

\subsubsection{Pedestrian Infrastructure}

Many factors influence a person's decision to walk to a destination, rather than driving or other modes. Research conducted by transportation specialists, including Reid Ewing at the University of Utah, shows that some of those factors include the "Ds": density of destinations, diversity of uses, street design, accessibility to destinations and distance to transit (Ewing and Cervero 2010).

The west side is stronger in some of the Ds than others: its population density is fairly low, as is diversity of uses since residential and commercial are generally separated. Destination accessibility is stronger for areas near TRAX and bus stops and downtown is only a few stops away. TRAX is the most reliable mode of transit, but buses cover a broader area and are the only effective way to travel north-south and to a large number of destinations not near rail stations. North Temple has a number of destinations that residents can easily walk or take transit to, 
including the Fairgrounds and popular restaurants like Red Iguana. There are also nice views of downtown and the mountains and some historic architecture. Many sections of the road, however, are in a transitional state, with primarily auto oriented strip mall developments mixed with hotels and apartments, industrial work sites and a few newer transit oriented developments. Most of the surrounding streets are residential housing built after World War II, with relatively small lots compared to newer suburban development, which generally makes them very walkable.

Pedestrian infrastructure along North Temple is modern, uniform and well maintained, with mostly wide sidewalks, landscaping that buffers pedestrians from traffic, easily visible traffic signals and ADA compliant features. There are twelve marked crosswalks within two miles of the Jordan River Parkway Trail/North Temple crossing, eleven of which have suitable markings and symbols for pedestrians. These includes visible, tactile paving to indicate boundaries, traffic control lights and crossing countdown beacons, yellow crosswalk signs and painted markers indicating where drivers should stop. However, crosswalks on other major west side roads, particularly Redwood Road further west, are often inadequate, with missing signals, poor marking and a lack of maintenance.

Based on onsite analysis, it is clear that North Temple has made strides toward to being a more walkable place, although it will take time for Transit Oriented Development (TOD) to catch up with street improvements. However, the intersection of North Temple with the Jordan River Parkway Trail is far from ideal for trail users. Currently, they must divert from the trail and cross at 1100 West, at an area adjacent to an open industrial area to the south and the Fairpark to the north. The current conditions should improve by 2018 when a planned pedestrian bridge is expected to open.

\subsubsection{Pedestrian Count Observations}

Westside Studio observed pedestrians along North Temple and noted several trends worth reporting. The subjective experience was that in spite of sidewalk improvements the environment can feel foreboding and uncomfortable for pedestrians, due primarily to the auto oriented streetscape and lack of destination density. Foot traffic was light, consisting of a few families and scattered people, including several apparently homeless individuals who traveled up and down the street.

\subsubsection{ADA Compliance and Safety}

North temple meets many requirements that the 1990 Americans with Disabilities Act (ADA) sets for street and pedestrian access. Per ADA, there should be a continuously accessible and level pedestrian route with detectable crosswalk warnings, appropriate space allowances and ramps for wheelchair access (Kockelman 2001). Wide, unobstructed sidewalks are also very important to allow for greatest access.

Along most of North Temple, sidewalks are twenty feet wide, well above the minimum fivefoot clearance required for pedestrians using mobility devices. One exception is outside the Fairgrounds, where the sidewalk is exactly five feet wide. Our observations, however, indicate that the design and location of that stretch of sidewalk makes it too narrow for many people to comfortable traverse, particularly in groups. 
There are pedestrian crosswalk warnings all along north temple, including marked crossings and tactile pavement changes. Many crossings have landing areas with truncated domes, raised areas reminiscent of LEGO bricks, which can serve a vital role for people with sight impairments. For the hearing impaired, crosswalk tones such as automated beeps or chirps have been implemented across the city and should be included in every North Temple crossing.

North Temple has had pedestrian countdown timers, which alert walkers about how much time they have to cross the street, installed at all major intersections since 2000. The amount of time given to each timer changes depending on the time of day and traffic flow in the area. In some cases, this can place pedestrians in difficult situations; for example, a timer at 900 West gives only three to four seconds of the "walk" signal before counting down, although pedestrians must cross four lanes of traffic. These signals should be periodically evaluated to ensure that users are able to cross safely, especially those who are in any way movement impaired.

\subsection{SUMMARY OF BARRIERS TO ACTIVE TRANSPORTATION}

While the pedestrian and biking infrastructure along North Temple is generally very good, there are barriers that limit their use and desirability, which can inhibit foot and bike traffic. This includes high auto speeds, lack of destinations on many blocks, empty buildings and parking lots that create a sense of limited enclosure. Infrastructure along other streets is variable, with crossings inhibited by barriers like Interstate 80.

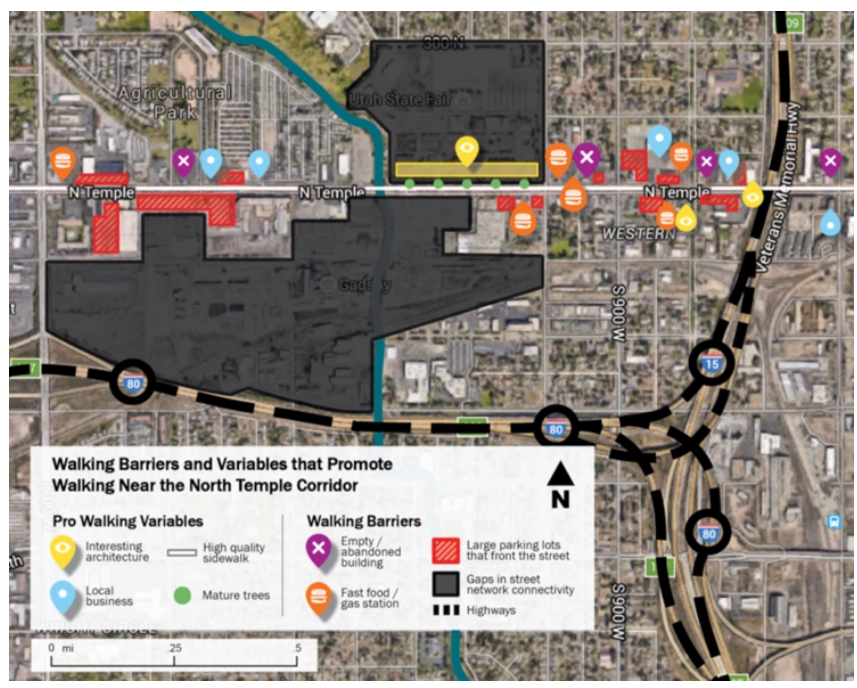

Figure 2: Barriers to walking along North Temple 


\subsection{TRANSIT AND HOUSING}

Land use planning has undergone a paradigm shift over the last several decades, with the focus shifting away from low density, leapfrog segregated development patterns in favor of a more compact, mixed use and clustered development patterns. This happened because of growing concern over urban sprawl and its environmental, health and social equity consequences, as well as a general recognition that complete personal automobile dependency may not be sustainable. Transit can act as a catalyst for this kind of clustered development through TOD, which aims to create clusters of destinations around transit stops. An effective transit system can also connect and reconnect segregated neighborhoods.

Transit in Salt Lake City is managed by the Utah Transit Authority (UTA). One of UTA's ongoing goals for its regional transit is to increase transit ridership, which has expanded consistently over the last several decades. The west side is a good candidate this goal, thanks to new infrastructure related to TRAX and the area's close proximity to downtown. Along with buses

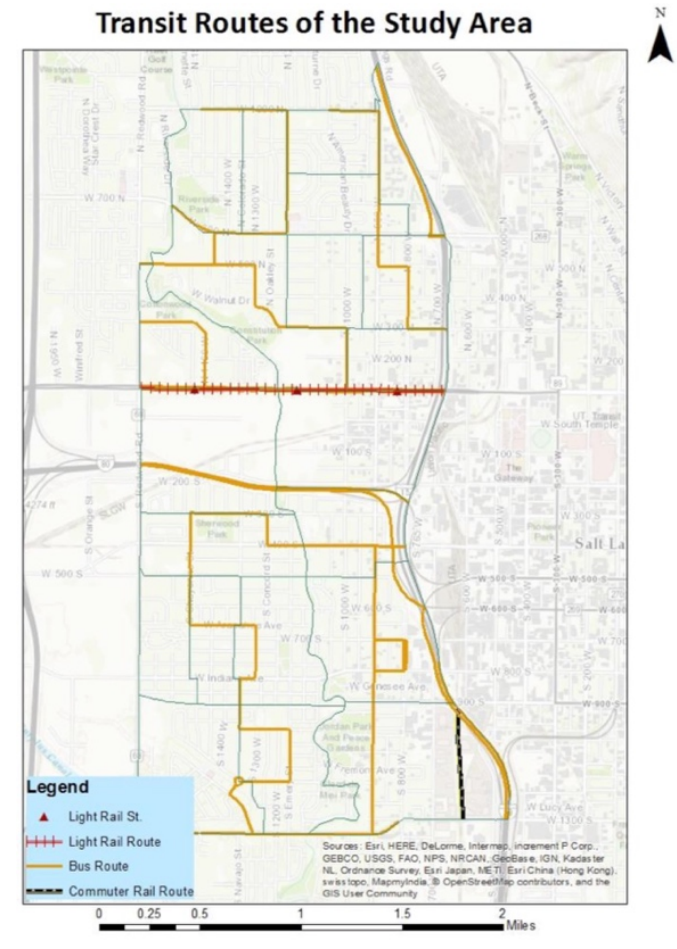

Figure 3: Transit routes on the west side and TRAX, UTA also manages Frontrunner-a commuter rail system that connects Salt Lake with counties to the north and south along the Wasatch Front. Frontrunner is accessible from the west side from the North Temple station, which connects to the TRAX Green line and from Salt Lake Central, which is just east of the freeway at about 300 South and is the terminus for many local bus routes.

\subsubsection{Transit Stations and Bus Stops}

Bus stop quality in the west side is variable, with many stop lacking amenities like benches, shelters, trash cans and concrete landing pads. This can make it difficult to access stops, especially for disabled individuals and make stops feel unpleasant and uninviting. Lighting is also variable, both at bus stops and along pedestrian routes on North Temple, which can create a perception of danger and decrease the aesthetic appeal of stops. UTA bus stops do not show route maps or schedules, although bus routes and locations can be located from its website and by texting route codes found at every stop.

TRAX stations provide more consistent amenities like trash cans, shelter and benches, along with clear route maps. The west side Green Line trains are also low floor models that can be boarded by wheelchair from the regular station platform. TRAX stations are also well lit, although the sidewalks surrounding them can be inconsistent. UTA transit also accommodates 
bike users with bike racks on the front of buses and designated bicycle spaces on TRAX and Frontrunner trains.

\subsubsection{Housing Density}

One impediment to housing density arises from housing densities: neighborhoods with high density and TOD are easier to serve with transit, while lower density areas are difficult to connect efficiently.

Based on the data gathered by Westside Studio, there is no particular pattern of density surrounding the TRAX light rail corridor, although all nearby census blocks are only light to moderate density. According to urban advocates like Peter Calthorpe of the Congress for New Urbanism, the minimum net density for urban livability should be around 10-15 units per acre, which is higher than any census block on the west side (Calthorpe 1995).

\subsection{STREET DESIGN}

In order to evaluate walkability and pedestrian comfort, it's helpful to look at a range of qualitative elements planners often use to analyze streetscapes
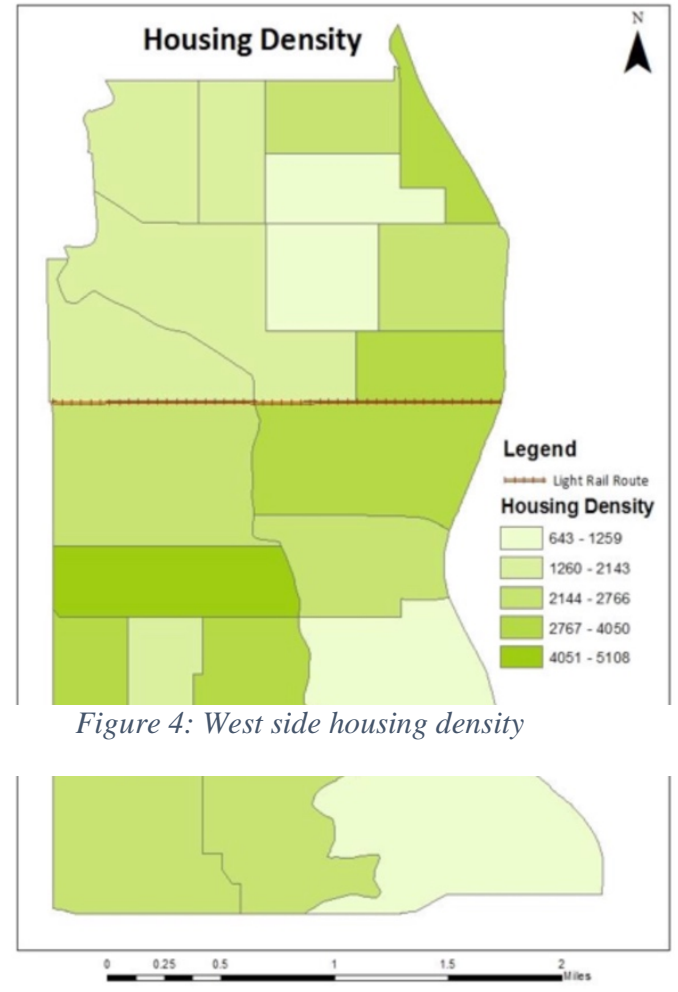
and urban designs. Westside Studio studied North Temple near the Jordan River Parkway Trail to evaluate several of these elements.

\subsubsection{Human scale}

Human scale means that objects and buildings along the street should be scaled for pedestrians, with buildings close together and signage and amenities designed for walking (Stephenson 1992). The area around North Temple, by contrast, is generally scaled for automobiles. The majority of buildings are short and widely spaced, which makes the wide streets feel even wider. Street furniture is sparse and there are many billboards and large retail signs designed to be viewed at high speeds. While newly redone sidewalks and crosswalks have improved the pedestrian experience, improving the street's human scale will take time and new development priorities that focus more on pedestrian needs. Nearby residential streets are generally more human scaled, with homes fairly close together, narrower streets and short fences acting as a buffer between spaces.

\subsubsection{Transparency}

Transparency refers to the degree of permeability between the private and public realm of the street, or the ability for pedestrians to window shop and see inside buildings from the street, which provides more visual interest than blank walls and parking lots and draws people to streets. The majority of buildings along North Temple are oriented toward the street, although 
most are set back by parking and other barriers, which severely limits transparency and there are few traditional shops or retail locations that offer much of interest to pedestrians.

\subsubsection{Enclosure}

Enclosure refers to how vertical elements define and outline the street space, operating on the principle that people prefer walking along the edge of an open area rather than feeling exposed without tall objects nearby. Buildings, trees and light fixtures can all contribute to a sense of enclosure along parts of North Temple, although this is undermined by parking lots next to sidewalks and wide gaps between buildings that limit the ability of streets to form a continuous "wall." The width of the street also affects enclosure and shorter buildings can contribute to a feeling of exposure along wide streets like North Temple.

\subsubsection{Complexity}

Complexity means having objects on the street that engage the senses while still being coherent. This includes murals, colors, furniture, signage, building facades and lights. In general, people prefer to walk in areas with greater complexity. North Temple's auto oriented development patterns make this difficult to achieve in many areas, although projects like the colored cement of TRAX and landscaped buffers between the street and sidewalk make the street more interesting to walk along. Architectural variety also helps, although many of the buildings on North Temple are low and box shaped with little adornment. Residential streets nearby tend to be more complex, with multicolored homes, trees, gardens, porches and other visual elements that grab the attention. 


\subsection{LEARNING FROM THE COMMUNITY}

\subsection{COMMUNITY ENGAGEMENT OVERVIEW}

As part of Westside Studio's emphasis on uses of active and public transportation along North Temple and the Jordan River Parkway Trail, focus groups and community surveys were conducted with neighborhood residents. They gave feedback on a number of social, economic and environmental issues, as well as planning topics like accessibility, walkability, safety and signage. In particular, they were asked about the Jordan River Parkway Trail and the North Temple corridor and how to encourage more use and better connections between the two.

Residents expressed concerns that ranged from safety, lighting, homelessness, wayfinding and destinations. Their feedback, particularly from surveys, indicates that the way people use North Temple and the Jordan River Parkway Trail tend not to overlap, with the former being mostly functional and the latter mostly recreational. This may actually indicate opportunities to better integrate the two and it should provide valuable insight for future projects.

\subsection{FOCUS GROUPS FINDINGS}

As discussed above, this research project employed focus groups to assess the resident's access to active transportation and transit choices and connectivity of two community assets - the Jordan River Parkway Trail and the North Temple (TOD) corridor. Focus group research included a wide range of user groups and voices in the study area. By employing focus group research, were able to obtain first hand impressions of the residents on their interaction with these amenities. Focus group methodology also helped us assess how visible and important are these two community assets. Many community members use both amenities frequently for active transportation and taking transit. This speaks of some level of success in the planning efforts that have taken place in the area.

We were able to find out from the focus group what encourages/discourages people to walk and bike in the area. Participant feedback was broadly grouped into three main categories: neighborhood assets, challenges and opportunities. Looking at assets first helps to frame the discussion around a positive view of the area, focusing on what residents like about the neighborhood before addressing problems. Participants also provided ideas for short term and long term improvements. Given that the study area is racially and culturally diverse focus group methodology proof to be a form to start and continue a conversation among stakeholders, community leaders and residents on how to encourage active transportation and transit use in their neighborhood.

\subsubsection{Perspectives on Assets}

\subsubsection{Neighborhood Assets}

Several residents described the west side as a "hidden gem" or "little hidden secret in the city" because is people are friendly, the neighborhoods are affordable and it has a number of amenities that those outside of the neighborhood do not know about. A resident said, 
The west side is one of the best kept secrets in Salt Lake City. It has great ethnic, cheap restaurants and housing is very affordable. The Jordan River Trail is an amazing asset. This neighborhood has tons of parks everywhere. Is easier to walk here, with grocery stores, small and big at a walking distance. I like the fact that there is an actual community, I walk to the store and see my neighbors there. They always say hello, in their backyards, in the supermarket, they just honk on the street and say hello. Is just a matter of time until young professionals' start moving here in huge numbers, because is so close to downtown and you can just take TRAX to work if you live near North Temple; you are already seeing some of that of course, with all the new developments going on.

Several residents mentioned that they appreciate how the west side neighborhoods surrounding North friendly, inviting places where residents know who their neighbors are and say hello to each other. While discussing about the urban amenities and the streetscapes, participants enumerated all the services they can access within the neighborhood including places to live, eat, exercise, swim, walk dogs, learn, work, and attend festivals. Some of the places that were mentioned were the Sorensen Multi-Cultural Community and Fitness Center, Northwest Recreation and Community Center, the Utah State Fairpark, the Glendale Library, the Farmers Market, Red Iguana, Mestizo Café, TRAX, North Temple and the Jordan River Parkway to name a few. They also enjoy its diversity and the opportunities to interact with different cultures.

In the news the west side has this bad reputation, that is poor, that is criminal, but there is more crime in downtown and in sugarhouse. They say that because there are immigrants and refugees here. The reason is that they are racist. There is Latinos, Black people here...so that is all it takes. Racist do not know they are racist, but they are. This is the only neighborhood in the city I would tolerate living in. Because is diverse. My neighborhoods are from Thailand, Ethiopia, Tonga, Mexico...you cannot find this kind of cultural diversity anywhere else in all of Utah! This place feels urban. I can interact with all kinds of people and I enjoy that.

Adding more on the defining character of their neighborhood many residents mentioned the opportunity of living in a community that houses rich diversity of race, ethnicities and cultures. According to them, learning about a new culture is as approachable as venturing out the neighbor's front doors in the area. The diversity is discernible from the decorations of the houses as someone walks down the street. The participants also think highly of the area's architecture as they used words such as "stunning" and "varied" to describe them. An elderly woman commented,

I enjoy walking on my neighborhood. I walk sometimes along the river and in North Temple, but not a lot. I mostly walk on my neighborhood. I like looking at the decorations people put. Some lady has the virgin Mary, some have Tibetan flags, all kinds of flags. In the summer people hang out on their balconies and front yards. Although some houses are falling apart, many houses all well-kept and have amazing gardens, which makes it entertaining to walk. Some of the architecture is remarkable, even if some of them were mass produced back in 50s. They are not monotonous, there is variation of materials 
and colors [...] I am not walking with a destination, I am old and I do not walk far, just around my routine blocks, sometimes I change it. I just do it because is entertaining and I know is good for my health.

\subsubsection{Jordan River Parkway Trail as an Assets}

Focus group members discussed the variety of ways they use the trail or have seen others using it, including as a route for commuters, as a path to get kids to school and as a place for exercise, dog walking and general recreation for individuals and families. It also provides a convenient way to access popular destinations on the west side, including the Sorensen Community Center, the Glendale Library and the Uintah Brewing Company. One resident commented,

My kids and I use the Jordan River Trail for recreation and utilitarian purposes. Using the trail, I go from my house to North Temple, or from my house to the Smith's (full-sized supermarket) which is in 600. There are various restaurants close, and to the North Recreational Center. I never walk without a place to go I am going to the store or somewhere. I could take the car, but I enjoy walking because is good exercise and me and my family use it as a way of free entertainment. Is better than driving to the movie theater. We watch the ducks, the birds. We do not even have a dog, yet we sit in the dog park to see the dogs play, we sit for 20 minutes and go back home; is just a form of entertainment for us.

A mother of two elementary school children added,

My two boys actually walk from my house to Backman Elementary School, one is seven and the other one is nine and they are very independent. Is great because they can go up and down without interacting with any cars. Sometimes they take their bikes, I do not worry about it because I know they are safe. If we were in Tijuana, I would not let them. There are laws and regulations, this community is very safe, so I let them.

As well as bringing comfort and convenience in their daily life the environment adds to their psychological health. Some participants pointed out how watching the evolving appearance of the river with the transitioning seasons was a defining character for the area.

The Jordan River Parkway Trail is one of the exiting things about living in this community. A lot of people who live in Utah like to hike, they drive to the mountains and the go for a hike. I just have to go around the corner and I can walk and experience nature. I like the outdoors all year around, when is snowing, then is hoy in the summer. It is really something to see. The change of the seasons is something to really see and experience. You can get away from everything else and enjoy nature in the middle of the city. 


\subsubsection{North Temple as an Asset}

Community members understood the value of North Temple being Transit Oriented Development in terms of walkability, convenience of shopping and restaurants, close to transit and downtown. A resident who lives in some new apartment in the area commented,

It this this is a very walkable area, to get great food. Even if you do not walk, you can drive and get what you need which makes the neighborhood much better than living in a suburban development. It is also more affordable and denser than most neighborhoods, there is some shops, and restaurants. Of course it has TRAX, which I think is the main amenity. You can take transit to work downtown. Is a great investment and now there is more housing being built here like where I live. Hopefully in the future business will also want to invest in North Temple. It's a future investment that hopefully will pay off in the future.

A lot of residents noticed that the city is investing in the area. The train is an example of that as well as a concerted effort to develop mix-use apartments to support the TOD. Locational wise North Temple is just outside of the city center that it was dilapidated before TRAX were installed. This investment was propelled, in part, because of the international airport. A resident explained how the station links the international airport to downtown and how it helps tourism,

North Temple is the only identifiable place in the west side. Is visible because of the train. You can go to the airport. Actually if someone is visiting Salt Lake City, the North Temple area is the first place that they would see. So it is the first face of Salt Lake City for visitors. If tourists are looking for a cheap place to stay the motels here are way cheaper, some of them are ok, like the Econo Lodge. From here they could get to downtown.

The stations in North Temple provides great connectivity to the airport and downtown. Some business owners have seen the potential of this opportunity. A neighbor explained,

There is a business owner who saw the potential of this is a transportation hub and they located their business here because of TRAX and the airport, he says that is better than downtowns, because he can just hop on the train and get to the airport. He travels a lot of his business. Some of his clients come to visit and he takes them for a walk to Red Iguana. There is a Hilton right across the Bridge at walking distance, so he puts them there. He says that is just a matter of time until other people see the potential of North Temple as a transit and business hub.

Residents spoke about the convenience of the area and the design,

Something I like is that there are complete streets. Those that do not have a car or can have a car like disabled people can move around safely instead of riding on the street, like they do on $600 \mathrm{~N}$. There are bike lanes too. The urban design is quite nice, there is some street art, plantings and trees. Some developers are restoring the area or building new apartments. There is more density being added, which hopefully will result in more pedestrians and more 
vibrancy in the area. This is why I chose to live here instead of some suburb, because, is within the city limits, small mom and pops, close to the interstate and close to Downton.

A lot of people talked about how the street has changed before and after TRAX. People seem to agree that this is a friendlier environment for walkers, cyclist and transit users. The redesign has added amenities that did not exist before and it expected to be a catalyst of even more amenities like restaurants, housing and shops.

\subsubsection{Perceived Challenges and Opportunities}

\subsubsection{Safety and Cleanliness}

The primary concern of focus group participants discussed was the feeling of safety, especially on the trail. This includes spots that are under lit and concerns about homeless people congregating in certain areas to camp. One Hispanic woman expressed,

I was walking in the middle of the day with my husband and kids we went by a tent. This homeless American older woman came out of the tent and she started to yell at us, she seemed very upset...she was obviously mentally ill. I know she is vulnerable to perhaps other homeless people, men, attacking her, because she is a woman. No one should be homeless, but especially women. I still walk there even if she yelled at me and my husband and children because I enjoy walking in the trail after dinner. But I can see how her presence would deter others from walking by, especially women walking alone or children.

A female runner expressed,

I always go running south to where I live on the trail, because I know that North is close to North Temple, where there is more homeless people. They camp under several of the bridges on the river. So, I know to avoid the north side and always go south. I do not even try to go north anymore.

Participants although some seem to acknowledge that homelessness had the right of using public spaces and residents' concerns and opinions on the issue differed within the focus groups. Other people commented about illegal behavior on the park. For example, people getting drunk in the park. One gentleman discussed his opinion on the matter,

I am not afraid of walking in the area. I know where they hang out. A lot of them are not even homeless. You see close to the park in Rose Park. Right there in front of the playground, these Latino men that are always hanging out under the tree, in the benches. They get there with their bikes. They just hand out and drink and play loud music. Sometimes in the middle of the day, you would see someone pass out on the bench. They are not harming anyone, just themselves. I still do not like it because there are children around and they are not a good example.

A similar theme of people not feeling safe emerged when discussing the North Temple corridor. One participant added to the conversation, 
So, during the day, I am fine, I would walk to restaurants near my house or to the supermarket. I would not walk pass 9 or 10 at night. I would prefer to drive than to walk at that time. I would drive to the closes restaurant-which is about a block and half from my house after dark. I feel is unsafe to walk. There is a high homeless population. I am not sure if to say they are homeless, because many of them are living in the motels. North Temple is full of these motels and something needs to be done about them, because they attract crime and prostitution. The amount of prostitution going on contributes to the crime in the area, with pimps, drug dealers and so on.

A young woman added,

I am afraid to be mugged and assaulted. One time this guy stole my phone. It was not a big deal it could have been worse. But there are all these people always asking for a quarter, for something to eat and I have been harassed, men yell this and that.... and I have been followed before when I am walking by myself. As a young woman is kind of scary. One time I was running with my girlfriend pretty early in the morning, like at 6:30 a.m. and I swear to God this guy was [doing something indecent] in front of a shopping cart. This is why a long time ago I got a running buddy, because you cannot be by yourself late or early in a supposedly busy street.

Another young woman added,

I would not walk around when is dark unless I am with my boyfriend. The other day two men were fighting in the middle of the street. One was on top of the other one just beating him up, they were obviously drunk or high. All kinds of people from the motels were just staring in a big circle, like in high school. My boyfriend and I just kept walking on the sidewalk, like nothing was going on. No sign of police around. Is not like is the first time I see something like this going on. So, thank God that it was not some kind of shooting. I am afraid to be at the wrong place at the wrong time, you know what I mean?

Also related to safety is cleanliness, with participants concerned that some sections of the trail feel run down or dirty, or have uneven or broken pavement. One person who lives near the trail commented,

The place gets full of trash and there are trashcans anywhere, at least that I am able to see. Some of my neighbors at the school organize a clean-up once a year in the summer. We come and clear about a mile of the trail near the school and invite parents to join us, lots of people come. Last time we got like 20 big trash bags! I wish we could get into the river, there is things that people thought in there, near where I live there is at least two shopping carts. One time someone left a boat and I had to call the city, so they came and remove it.

Some of the same issues take place in North Temple, as one man that lives in the new development near 600 West and North Temple, which is close to a freeway underpass commented, 
I see a lot of trash under the underpass, there is tons of trash there, clothes, shopping carts you name it. There is a lot of those red caps for needles too, so you know that people are shooting up, right? The health department and a volunteer neighborhood watch group every couple months cleans up the area. I think they clean it up a couple months ago and if you go now, it looks like it has not been clean in a year.

Safety concerns also apply to traffic. One person commented about North Temple,

The city made all these street improvements since they added TRAX, there are a lot of lights, instead of suggestive stop signs in the crosswalks. So, the infrastructure is there, that is not the problem. The problem is cultural, people are always speeding, running red lights with complete disregard to human life. Drivers are extremely dangerous. This makes me feel unsafe, but I am extra cautious, I never think that is my "right" to walk (even if is my "right"). I wait until I see that the driver has slowed down and then I walk. I am extremely cautious.

Along the Jordan River Parkway Trail, particularly along stretches where lighting seems arbitrary to drivers, cars tend to speed and ignore traffic signals,

I run in the trail at least three times a week, but my route intersects several flashing lights. I have to push the button and wait until the light changes and make sure cars notice I am there. You have to remember that cars are just speeding from several miles before and they are not approaching any major intersection, there is not traffic lights indicating that they might have to stop a half mile from the trail if there is a pedestrian. Many times I push the light, the flashing lights come on and the cars keep going. I am not sure why, most cars would stop, but some would just keep going.

Another participant added,

I think that North Temple is the best street from the pedestrian infrastructure perspective. The sidewalks are big and comfortable and there is a lot of places to cross. For the most part I am not afraid of being killed while walking. I would not say the same thing of biking. Yes, there are bike designated lines, painted on the pavement., they are not protected like in 300 S. There are also bike traffic signals, which are pretty modern, because I have not seen them in other parts of the city. I am not sure why the city did not make protected bike lanes because the sidewalks are so wide. They could have shared some of that pedestrian space with bikers. The end result is that I bike on the sidewalk. I see a lot of older people like me, women and children doing the same thing. Some people do not like it, but at least I get to live!

\subsubsection{Connectivity and Wayfinding}

Much of the focus group discussion revolved around ways to make the Jordan River Parkway Trail accessible for residents and new users. Some were unaware of the trail or uncertain how to 
access it from North Temple, which could be improved by clearer signage and better pedestrian crossings. One participant said that,

I have encounter many neighbors that are not even aware that the Jordan River Parkway Trail is in their backward. I tell them where is the nearest entrance and they cannot even picture it. I am not sure if is the lack of interest, you know some people do not like to walk further than maybe their own block to walk their dogs. But I think that if there was signage, showing entrances, at least people would know where it is.

\section{Another participant commented,}

We are right now sitting at the North Rec Center right? We are just a few steps to the Jordan River, most people do not know that. Tons of people use the Rec Center daily, probably hundreds and they do not know. They drive, park and exercise inside, when there is a nice trail to run and walk right there. They probably do not know about it. Someone should put a sign at the North Rec Center that says, hey do you know that there is a trail right in our backyard?

A young woman added,

Ok, so this new year I started to exercise by going to Zumba at the North Rec Center and I said to myself: instead of driving I will run through the trail to my Zumba class. I budgeted about half hour, so I thought that would be plenty of time because I live about 10 minutes walking from it, when I use the streets. Running there is very different than when you go on the streets there are a lot of trails going everywhere, nothing is a straight shot. So, what happened: I got lost! I left my phone at home cuz I am running and I do not want to carry stuff. Next thing you know, I am lost! I am desperately looking for a sign, a map, and there was nothing. I kept asking people, how do I get to the North Rec Center? And they did not know, so no one was able to help me out. I barely made it to my class, but the thing is that I was desperate trying to find it and I could not. Now I know the route, so it is ok. But the point is that if this is your first or second time...I used the trail for years and I could not remember specifically how to get to the North Rec Center, because I never tried before.

Participants also talked about improving signage along the trail itself, including mile markers maps with nearby destinations, creative signage and murals and more clearly marked access points.

When you get into the trail there are not maps that show where to go (destinations on the park) like where are the dog parks, picnic tables areas, bridge crossings...You cannot place yourself on the neighborhood. You cannot tell which intersection you are going to hit, unless you are accustomed to walk on the trail. For people who are here that works, but I see a lot of these bikers that just use the trail for recreation. Maybe if they knew that the supermarket is here, there are good restaurants nearby, a recreation center, maybe they would actually visit the community as opposed to stay in the trail. They can ride TRAX if they need to. 
Better signage for park rules could also notify users about the prohibitions on camping and motorized vehicles on the trail and about trail etiquette among bikers and walkers. Focus groups also talked about gaps in the trail and sections where street crossings are inconvenient, including when the trail intersects with North Temple and other major streets. Finally, for cycling enthusiasts one issue is that the trail doesn't connect to the canyons, which a new trail along City Creek or Millcreek might resolve.

Most people agree that connectivity regards to sidewalks is pretty good in North Temple. The major barriers that bikers and walkers experience is between $400 \mathrm{~W}$ and $500 \mathrm{~W}$, where there is bridge,

There is a problem when it comes to connectivity is between the west and the east side of the rail runner, which breaks the city in half. Bike lanes disappear because there is not enough space, so sidewalks disappear too, you have to choose your side of the street. It just makes it inconvenient and uncomfortable to walk there.

The lack of proper pedestrian connectivity and sidewalks in that area makes this freight train a barrier for walkers and bikers. Marmalade Branch Library, which is a great designation for the residents, almost becomes unattainable via walking due to the lack of continuity and convenience on that section of the neighborhood. This issue was specifically discussed by one of the focus group participants as he recalls his walk trip to the library with his family and the freight train rail lines impeding their stroller access,

If I had the option of not walking on the train line, I would. I wished there was another route I could take because it feels unsafe to walk over several double sets of tracks, maybe a train would come, I know it has surprise me a few time. Maybe crossing gates would make a difference? I also walk with my stroller all the time, and that particular spot is very hard to walk with my stroller. I am thinking that maybe a pedestrian bridge would fix the problem?

\subsubsection{Pedestrian Engagement, Destinations and Events}

Many of the focus group participants were enthusiastic about biking along the trail and North Temple, but felt that there was a shortage of quality destinations nearby. A few businesses like Red Iguana are popular and it was suggested that more businesses along the corridor would draw pedestrian and cyclists, as would a park comparable to Liberty Park, a popular park with a variety of amenities on the east side of the city.

The one thing that we have that is attractive to the rest of Salt Lake City is Red Iguana. That is the only place that would make people come from the east side to the west side. People are willing to make a line for hours to eat there, even if is next to that crappy motel. The motel is not a detractor for people to be there at all. All we need are more places like Red Iguana! People then would say, hey, the west side is the place to be. They would not just drive to Red Iguana, they might drive there, sure, but then they would walk to other attractive places. As of right now, we only have the Red Iguana, that's it. 
Regarding North Temple another participant added a thought about the lack of pedestrian engagement and destinations,

There is no pedestrian engagement in North Temple. The city has tried to solve this by requiring a percentage of glass on the bottom of buildings, entrances every couple of feet, landscaping and so on. Mixed-use is kind of impossible in this neighborhood. There is only one coffee shop on the west side and we are sitting on it. Is the only coffee shop in this whole side of town! Ask the owner about it. This place is being subsidized by NeighborWorks, because they believe this is a catalyst for the rest of the west side. After you pass City front, with this coffee shop and apartments, there is nothing that engages the pedestrian. Most storefronts are vacant.

A representative of NeighborWorks, a Community Development Corporation added,

Something we have tried to do is encourage business owners to improve their façades. Many of them have taken advantage of our program. One problem is that we do not have a lot of money, it is very expensive to replace a wall with a window. We are only able to cover a small percentage of their cost. Many of these business are good neighbors and they are open to make changes to make their property look better.

Another participant added,

North Temple has great sidewalks and the train is there, but it doesn't have places to go. I usually drive everywhere. I drive to the Rancho Markets and I also drive to the restaurants. All the restaurants have a drive through so it is very convenient to get in and out in your car. If you are walking is uncomfortable precisely because all the cars are rushing to and from the drive through. A while ago the city passed an ordinance to get rid of the drive through because you could even get a quick loan or buy cigarettes while sitting inside your car.

As discussed on the previous section, many community members do not know where is the trail. A number of focus group participants suggested to hold events on the trail so people made an effort to find it and get there,

There are several events that bring people to the river already. This is a way to educate the public about different pocket parks and destinations within the trail. Maybe at these events people who biked and walk would get an incentive-a raffle ticket, a free hotdog or something. This would be a way maybe encourage people to get to the event walking and biking.

A woman added,

There is a triathlon where people instead of swing in the river-which is extremely dirty and kind of disgusting people get in kayaks-then they do a $5 \mathrm{k}$ and then they bike a 15k. People from the neighborhood and outside the 
neighborhood come to the event. We need more events like this, so people get to know and use the tail.

While the participants were willing to bike or walk to events, they generally agreed that the nature of the event mattered more than how they would get there-biking and walking were matters of convenience, rather than ends in themselves.

I know a lot of people who park to then walk on the Jordan River Parkway Trail. There is not enough parking and if there is people have trouble finding it. The Jordan River is a destination on itself, so it doesn't matter if people get there on their cars, walk or bike. Once they are there they are going to walk, so just having more events and destinations, like more dog parks, playgrounds, would attract people. The events do not need to be about running or biking, maybe is a family event or a Latino fiesta, a BBQ, what matters is having events that are going to attract different groups of people, so they know where is the trail and they use it.

That indicates that planning a variety of events that appeal to broad segments of the community is one of the most important goals. There are a number of events that take place in the Jordan River Parkway Trail throughout the year. Focus group members specifically mentioned the Annual $4^{\text {th }}$ of July Parade on North Temple, along with the Get Into the River Festival, the Tour de Brewtah, the Salt Lake City Bike Party and the Skatenow skating/rollerblading event. They talked about their openness to more community based events, especially ones that might encourage more Latinos to use the trail. In order to bring more youth and parents to the area, participants suggested sporting events and another discussed neighborhood cleanup programs to develop more community ownership. In addition, more destinations like dog parks and playgrounds should naturally attract more bicycle and foot traffic. In regards to North Temple people mentioned that the Utah State Fair Park, is one of the greatest assets in area. Any given week, especially in the summer, there is an event taking place at the fairgrounds.

\subsection{COMMUNITY SURVEY FINDINGS}

To better evaluate assets and potential improvements along the Jordan River Parkway Trail and the North Temple corridor, surveys were distributed to residents about their use of active transportation options like biking and walking and what obstacles might deter them. The surveys were collected in March 2016 from 292 local respondents. The following is a highlight of survey results. Except where noted, questions allowed for multiple answers and some answers have been omitted or combined.

\subsubsection{Jordan River Parkway Trail use}

- $49.5 \%$ of residents surveyed live within one mile of the trail

- $10 \%$ use the trail daily

- $7 \%$ 4-5 times per week

- $11 \%$ 1-2 times per week

- $3-4 \%$ times per month

- $39 \%$ have never been to the trail 
- $9 \% \mathrm{~N} / \mathrm{A}$

\subsubsection{Modes of accessing the Jordan River Parkway Trail}

- $30.2 \%$ access the trail by driving

- $30.9 \%$ by biking

- $45.4 \%$ by walking or running

\subsubsection{Times of the day that respondents use the trail}

- $19 \%$ mornings

- $26 \%$ afternoons

- $25 \%$ evenings

- $7 \%$ varies

\subsubsection{Reasons for using the trail}

- $66.6 \%$ for recreation

- $12.7 \%$ for errands/grocery shopping

- $10.4 \%$ for biking to destinations

- $7.3 \%$ for walking to destinations

\subsubsection{Favorite aspects of Jordan River Parkway Trail/North Temple connection}

- $61.7 \%$ like that that it can be used for health, exercise and recreation

- $33.3 \%$ use it to avoid traffic/busy streets

\subsubsection{Significant impediments to using the trail}

- $32 \%$ feel unsafe

- $8 \%$ hard to access on foot or bike

- $8 \%$ hard to follow, insufficient wayfinding

- $8 \%$ limited parking

- $44 \%$ other

\subsubsection{Desired trail signage}

- $47.5 \%$ entrance and exit signs

- $45.4 \%$ trail mapping

- $36.5 \%$ local wildlife and vegetation facts

- $34.8 \%$ trail distance markers

\subsubsection{Environmental concerns}

- $65.4 \%$ litter

- $45.3 \%$ water quality

\subsubsection{Desired trail enhancements}


- $44.5 \%$ bathrooms, water fountains, trash cans

- $31.4 \%$ accessibility improvements

- $24.4 \%$ landscape improvements

- $20.4 \%$ safety improvements

\subsubsection{Ways North Temple is frequently used}

- $14 \%$ grocery shopping

- $27 \%$ visiting restaurants

- $23 \%$ taking TRAX light rail

- $16 \%$ going to work or school

- $8 \%$ retail shopping

- $9 \%$ do not use it

\subsubsection{Mode split to access North Temple}

- $57 \%$ drive

- $8 \%$ bike

- $13 \%$ walk or run

- $19 \%$ public transportation

- $3 \% \mathrm{~N} / \mathrm{A}$

\subsubsection{Frequency of transit use on North Temple}

- $39.2 \%$ never

- $29.1 \%$ more than once a week

\subsubsection{Ways of encouraging transit use}

- $32.2 \%$ if transit went more places I need to go

- $31.2 \%$ if stops were easier to get to from home

- $28.1 \%$ if transit was quicker than driving

- $26.8 \%$ if transit was cheaper

\subsubsection{Ways to encourage walking, biking and transit on North Temple}

- $47.5 \%$ entertainment options

- $42 \%$ retail shopping

- $33.2 \%$ community spaces

- $32.5 \%$ landscape improvements

- $24.1 \%$ safety improvements

\subsubsection{Types of improvements to encourage people to use active mode choices}

- $52 \%$ access to more amenities

- $23 \%$ streetscape improvements

- $17 \%$ accessibility improvements

- $8 \%$ other 


\subsubsection{Barriers to walking or biking along North Temple}

- $40.6 \%$ it's unpleasant

- $37.2 \%$ don't feel safe

- $34.1 \%$ not much to walk or bike to

\subsubsection{Desired North Temple Signage}

- $38.8 \%$ community amenities

- $38.8 \%$ points of access and distances to the Jordan River Parkway Trail

- $38.5 \%$ historical and cultural facts

The survey shed light on residents' views of the North Temple corridor and the Jordan River Parkway Trail, along with ways they might be improved. About $49.5 \%$ of residents surveyed reported living within one mile of the trail. In reality, $100 \%$ of people live in less than a mile, which means that people overestimated how far it is. The majority of residents (61\%) have used the trail at some point. We find that of those who use the trail about $40 \%$ use it at least one a week and of those $10 \%$ using it daily. Something that we found surprising is that about one third of trail user access to trail driving even if they live in the neighborhood. This demonstrates that the trail is a destination in itself. Still, the majority access is by active transportation—about $31 \%$ by biking and about $45 \%$ walking or running. The data shows that about $51 \%$ respondents use the Jordan River Parkway Trail in the afternoons and evenings. The majority of people access the trail for recreational purposes (67\%) while the rest (33\%) uses the trail to get to other destinations like grocery shoring, running errands, etc. When asked about the Jordan River Parkway Trail/North Temple connection, about $62 \%$ reported that they use the trail specifically for health, exercise and recreation while $33.3 \%$ use it to avoid traffic/busy streets. This indicates that the trail acts to some extend as community connector, precisely because people are trying to avoid traffic. Residents would like to see signage of: community amenities, points of access and distances to the Jordan River Parkway Trail, historical and cultural facts.

As asked about the detractor of the trail—respondents reported that the major was the safety issue. About 32\% of the respondents felt unsafe while using the Jordan River Parkway Trail, followed by other reasons which are limited parking (8\%), difficulty of using the trail on foot and bike (8\%) and inadequacy of wayfinding on the trail (8\%). People looked for trail mapping (45\%), trail distance markers (35\%) signage to know their entrances and exits (48\%) and surrounding features while using the trail like local wildlife and vegetation facts (37\%). When asked about environmental concerns the vast majority were concern with trash and litter (65\%). This is consistent with some of the desired trail enhancements being bathrooms, water fountains, trash cans (45\%). Others would like to see accessibility improvements (31.4\%), landscape improvements (24.4\%) and safety improvements (20.4\%). We would have expected safety improvement to be higher given that about $30 \%$ of respondent felt that safety was a concern.

When people were asked for reasons to go to North Temple taking TRAX (23\%) was only second to visiting restaurants (27\%), followed by going to school (16\%), go grocery shopping (14\%) and retail shopping (8\%), while 9\% do not go to North Temple even if they live in the neighborhood. Although 23\% go to North Temple to use TRAX and small percentage access it through public transportation (bus) (19\%), while $8 \%$ bike, $13 \%$ walk or run and the vast majority (57\%) drove. When asked about how often people use transit use on North Temple 39.2\% said that never, while $29.1 \%$ said more than once a week. Survey participants reported that they 
would be more inclined to use transit if: it went more places they needed to go (32.2\%), if stops were easier to get to from home (31.2\%), if transit was quicker than driving (28.1\%) and if transit was cheaper (26.8\%).

One of the questions was what would encourage people to walk, bike and take transit in North Temple. The majority people (47.5\% of the respondents) would like to see entertainment options, $42 \%$ retail shopping, $42 \%$ retail shopping, 33\% community spaces, 33\% landscape improvements, $32 \%$ landscape improvements and $24 \%$ safety improvements. When asked about biking and walking specifically people would like to see: more amenities (52\%), streetscapes (23\%) and accessibility improvements (17\%). The streetscape improvements were categorized here under landscaping improvements, cultural features such as murals and sculptures and maintenance improvements-trash and litter, snow removal, and so forth. This response is again indicative of how travel behavior is influenced by land use and built environment characteristics. More interestingly, it also shows how people's perception of a place is also determined by their perception of safety, as $17 \%$ of the respondents sought safety improvements such as more lighting in the area. survey respondent reported their major barriers to walking or biking along North Temple: $41 \%$ it’s unpleasant, 37\% don't feel safe and 34\% not much to walk or bike to. 


\subsection{DISCUSSION}

A major barrier to the pedestrian experience in the study area, for both the Jordan River Parkway Trail and North Temple is the perception that it is unsafe both in terms of criminal activity and traffic. This finding is similar to other studies in low income areas where there might be homelessness or land uses that attract criminality, like motels (Wood et al. 2008, LoukaitouSideris 2006). The streetscape improvements improvement (sidewalks, landscaping, TRAX, etc.) are all great amenities, but people still find that North Temple is lacking business and destinations. Because the area is low income it has a number of vacant buildings, huge parking lots and empty lots as well as uses that do not support walkability-quick loans shops, drivethrough, etc. These spaces do not add much to the perception of safety or walkability in their neighborhood.

Even if there is a lack of destinations, wide well-maintained sidewalks, ADA-compliant features, visible traffic signals, paved trails and the street furniture did invite people to walk and bike more in the daytime, but soon after it gets dark people are reluctant to take advantage of the few amenities that exists. Firstly, social maladies such as crime, drug dealings, and prostitution outweigh the attractions of the improvements. Residents prefer to drive to the area instead of walking, which contributed to the problem of surveillance. The underutilized North Temple corridor affects the pedestrian experience by lowering the amount of activity on the street, they. The mere physical improvements to the street do not add to the livability of a neighborhood if the resident's real challenges are not addressed (lack of business, etc.) and integrated as part of the planning process. This goes back to the literature, when compared to driving, people decide to take a walking trip to a destination based on more than a few factors. A study conducted by Ewing et al. (2005) identified five contributing factors of active transportation and transit use, which are-density, diversity (mix of land uses), design, destination accessibility and distance to transit.

Earlier study by McLeroy et al. (1988) showed how presence of parks in urban areas could influence encouraging physical activities, while lack of access to parks can discourage physical activity. In the survey we found out that about $40 \%$ of people who live in the neighborhood (which is about 1 mile at the furthest point of anyone) have never been in the trail. About $40 \%$ of those who have used the trail, use it at least one a week. This means that accessibility to park is not enough to attract people to the park. About one third of resident's drive to the park to use it for recreation. Another one third do not use for recreation, but use it to avoid traffic and get to other destinations-like schools, the North Rec Center or even North Temple. This shows that there are important connections between the trail and North Temple. Presumably, connectivity is good for the households that use the trail in this way.

Most people in the survey and the focus group reported that the is a shortage of reliable connectivity from the Jordan River Parkway Trail to the rest of the neighborhood, including North Temple. Wayfinding seem like a major problem in the trail, people knew where places are on the roads but not in the trail so they cannot get in and out where they want to be. According to participants, the lack of signage and exists and entrances could also be a reason why about $40 \%$ of residents have never been in the trail. An idea that was offered in focus group discussion was to hold events on the trail, where people where incentivized for walking or biking such as concerts, food trucks, beer gardens, outdoor movies, and festivals. 


\subsection{RECOMMENDATIONS}

Based on research and community input, Westside Studio recommends a number of improvements that can be implemented along the Jordan River Parkway Trail and the North Temple corridor. These have been organized categorically and are followed by a suggested framework for prioritizing and implementing recommendations.

\subsection{BATHROOMS, WATER FOUNTAINS AND TRASH CANS}

Survey responses indicated that many residents would like to see more basic amenities along the trail. Adding these should improve the trail's comfort and cleanliness and provide a better environment for recreational use, which is the predominant mode of trail usage.

Additional facilities require regular maintenance and cleaning, so they should be part of broader initiatives to invest in the park as an asset. More detailed study of design, placement and maintenance needs to be done, but in general they should be placed near trail entrances and in easily visible areas, which will encourage safety and responsible use.

\subsection{UNIVERSAL TRAIL ACCESSIBILITY}

Research indicates that that the North Temple and Jordan River Parkway Trail connection lacks accessibility features for some users, particularly those who are older or physically impaired. In keeping with the goal to make the area accessible to everybody, ramps and rails should be installed along trail entrances and exits and wherever there are significant grade changes. In addition, signage in braille and audio cues should also be considered. Additional outreach should also be made specifically to senior citizens and disabled residents to let them speak for their own needs.

\subsection{SIGNAGE AND WAYFINDING}

Surveys, focus groups and field observations indicate that wayfinding near the Jordan River Parkway Trail can be difficult and unintuitive, particularly for users who might try to access the trail from North Temple. Based on the goal of promoting and improving active transportation options, improved signage can make the Jordan River Parkway Trail more inviting and easier to access, particularly for user who don't know about or use the trail already.

Specific signage recommendations begin with marking trail entrances along North Temple and other crossings. The goal should be to clearly show where users can enter and exit the trail, which will help tie it to the city's broader transportation network and encourage walking and biking. Signs might also be used in conjunction kiosk or announcement boards to highlight events and amenities along the trail. Finally, good signage will help establish the trail as a destination, creating awareness among residents who aren't currently using it. Signage can thus act as branding and public education for city park systems and transit. Signs should be visible to pedestrians, cyclists and vehicles and should be visually distinctive from the surrounding environment. One possibility is a large, arching gateway sign over the trail entrance to create an obvious point of reference and mark a transition into the trail space. Making the signs graffiti proof (including replacing existing ones) can help create a sense of cleanliness and safety. 
Another recommended signage upgrade is trail mapping, which can show users where they are located along the trail, where they are in relation to the rest of the city and what amenities are nearby. The last function can be particularly useful if additional water fountains and bathrooms are installed. The value of trail mapping is that it helps users know what to expect and allows them to gauge their progress for walks, runs and bicycle trips, which should encourage active transportation uses.

While signs along North Temple might help new users discover the trail, good active transportation systems require destinations that users want to visit. That is addressed in part below, but signage can also play a role in notifying cyclists and pedestrians about amenities along and near North Temple, including shopping, restaurants, libraries, transit stops and points of interest. This, in conjunction with land use and economic development choices, can make the area friendlier for non-automobile uses, which benefits both residents and visitors.

\subsection{SAFETY MEASURES}

Safety was a theme that arose repeatedly in both surveys and focus group discussions, with some respondents indicating that perceived safety issues already affect how they use the Jordan River Parkway Trail and North Temple.

One issue is with limited lighting along the trail. Currently the trail gets very dark after the sun goes down, with little lighting along significant portions of its length. This may be, in part, a deliberate strategy to limit use of the trail after dark (most city parks are closed at night), but poor lighting can also deter use of the trail in the evening if users fear feeling "stranded" after dark.

A recommended solution is to implement more lighting along the trail, particularly around trail entrances and common gathering places. The specific placement and kind of lighting needs further study, but ground level, low wattage, solar powered lights along the edge of the trail are an option that would minimize electricity costs and limit light pollution. Better lighting would also help with wayfinding and keeping cyclists on the trail. In addition, improved lighting around trail entrances on North Temple will promote a transition between the trail and the street that feels safer.

Some respondents expressed concerns about homeless populations congregating along the trail. By nature, any new amenities that improve the comfort of the trail may also draw more homeless individuals. While resolving that is beyond the scope of this report, it is an issue that should be handled sensitively and in partnership with other city and nonprofit resources. Improved lighting should alleviate many safety concerns and that can be augmented by measures like regular police call boxes and clearly marked trail exit points.

The North Temple corridor also suffers from high levels of transitory populations living in the motels. These aspects detract from possible pedestrians from using North Temple after dark. Given these conditions and based on previous research, high density residential zoning and mix of uses facing the street would contribute to more watchful eyes on the street by creating more opportunities for recreation, dining, and entertainment in the area (Jacobs, 1961; Newman, 1972). This would intrinsically make the North Temple corridor safer for all users and subsequently reduce delinquent behavior. The basis of this recommendation is drawn from an existing example: the restaurant Red Iguana. Confirmed by the focus group respondents, it is 
believed that such uses can facilitate in surveillance of the street and promote a sense of safety. Secondly, it is suggested that the speed limit be reduced along the North Temple corridor.

Pedestrians using the trail felt that there were problematic intersections. Given that these streets have streetlights or flashing lights, is not clear how to improve those areas. Maybe adding signage before approaching the trail would be useful for driver. Enforcement might be also needed as drivers often times see the flashing light as suggestive. In North Temple, even with streetlights intersections are problematic for pedestrians as well, but they feel safer than cysts. Perhaps, dropping the speed limit by $5 \mathrm{mph}$ would create an environment more conducive to the needs and safety of cyclists. Adjusting this regulatory aspect would not just incentivize bikers to use North Temple more frequently, it will also encourage them to patronize the amenities and the businesses offered along the corridor. Slower streets, also rather intuitively are safer for all users, regardless of their method of transportation (car, bicycle or bus).

\subsection{ENTERTAINMENT AND DESTINATIONS}

Concerning the user survey, the highest number of respondents (47.5\%), favored more entertainment options to increase activity on the North Temple corridor. Lack of things to do along the Jordan River Parkway Trail was also the main point of concern. Energizing both the North Temple Corridor and Jordan River Parkway Trail through entertainment could enhance use by making the area a desired and pleasant destination. As amenable zoning practices come into play that allows more mixed of uses and increased density, they will be able to invite more residents and businesses into the area. Additionally, as high density residential and commercial zones arise, economic investments will take place to increase the accessibility and connectivity between North Temple and the Jordan River Parkway Trail.

Collaboration can be done with Salt Lake City to ensure its zoning and incentives are structured to encourage land use that complements active transportation in the area. In particular, the long term goal should be to shift from auto centric development to a more walkable corridor. While it's not usually possible to place businesses in specific places, planners and city officials promote the kinds of destinations that might improve the area, including pubs, restaurants, theatres, fun centers, grocery stores, coffee shops, bicycle shops, day cares and small ticket residential, among many others.

In addition to physical improvements and interventions, surveys and focus groups indicate that there are opportunities to actively draw people to the area. That includes promoting community and city activities that take place on or use the trail and developing businesses that meet the needs of trail users, especially families, nearby residents and outdoor enthusiasts. Any measures that boost North Temple as a destination can create cascading benefits for the Jordan River Parkway Trail by allowing people to use it as a means of traveling to and from the area. Currently the trail is most often used for recreation and not as part of an active transportation network, but destinations and events can help integrate it. 


\subsection{IMPLEMENTATION}

This section outlines an implementation overview that could be used to guide the recommendations detailed previously. Then, it recommends further steps that could be taken by future Westside Studio classes (or other workshops) to further address implementation of amenities in the area. Finally, it also details two implementation projects undertaken by students to help revitalized both North Temple and the Jordan River Parkway Trail.

\subsection{PROJECT IMPLEMENTATION PRIORITY TABLE}

Table 1: Prioritized recommendations for policy and project implementation

\begin{tabular}{|c|c|c|c|}
\hline Policy and Project Recommendation & $\begin{array}{l}\text { Total Estimated } \\
\text { Cost }\end{array}$ & Priority & Time Period \\
\hline $\begin{array}{l}\text { Wayfinding and signage for the } \\
\text { Jordan River Parkway Trail }\end{array}$ & $\$ 800$ to $\$ 3,200$ & High & Medium Term \\
\hline $\begin{array}{l}\text { Local event that includes incentives } \\
\text { for those who walk, bike, or use } \\
\text { public transit }\end{array}$ & $\begin{array}{l}\$ 1,000 \text { to } \\
\$ 5,000\end{array}$ & High & Short Term \\
\hline $\begin{array}{l}\text { Improve trail upkeep, paving and } \\
\text { lighting }\end{array}$ & Up to $\$ 800,000$ & Medium & Long Term \\
\hline $\begin{array}{l}\text { Modernize and improve amenities } \\
\text { along the Jordan River Parkway Trail }\end{array}$ & Up to $\$ 160,000$ & Medium & Long Term \\
\hline $\begin{array}{l}\text { Solutions for perceived safety and } \\
\text { homeless issues }\end{array}$ & $\begin{array}{l}\text { Further research } \\
\text { required }\end{array}$ & Medium & Long Term \\
\hline $\begin{array}{l}\text { Create more opportunities for } \\
\text { recreation, dining and entertainment } \\
\text { along North Temple }\end{array}$ & $\begin{array}{l}\text { Further research } \\
\text { required }\end{array}$ & Medium & Long Term \\
\hline Educational signs & $\$ 800$ to $\$ 3,200$ & Low & Medium Term \\
\hline
\end{tabular}

\subsection{SIGNAGE AND WAYFINDING}

Residents who use the Jordan River Parkway Trail agree that it is an asset to the neighborhood, but that it's underutilized and sometimes undervalued, to the point where many locals are unaware it exists. To improve wayfinding and awareness along the trail the Westside Studio course design, paid and install at the North Rec Center a sign that shows where the Jordan River Parkway Trail and North Temple is. Students also chose other locations. The idea would be to coordinate with appropriate stakeholders to having them installed. These signs could include 
information discussed previously in this report, including walking distances to nearby amenities, mile markers, trail entrances and exits and trail maps.

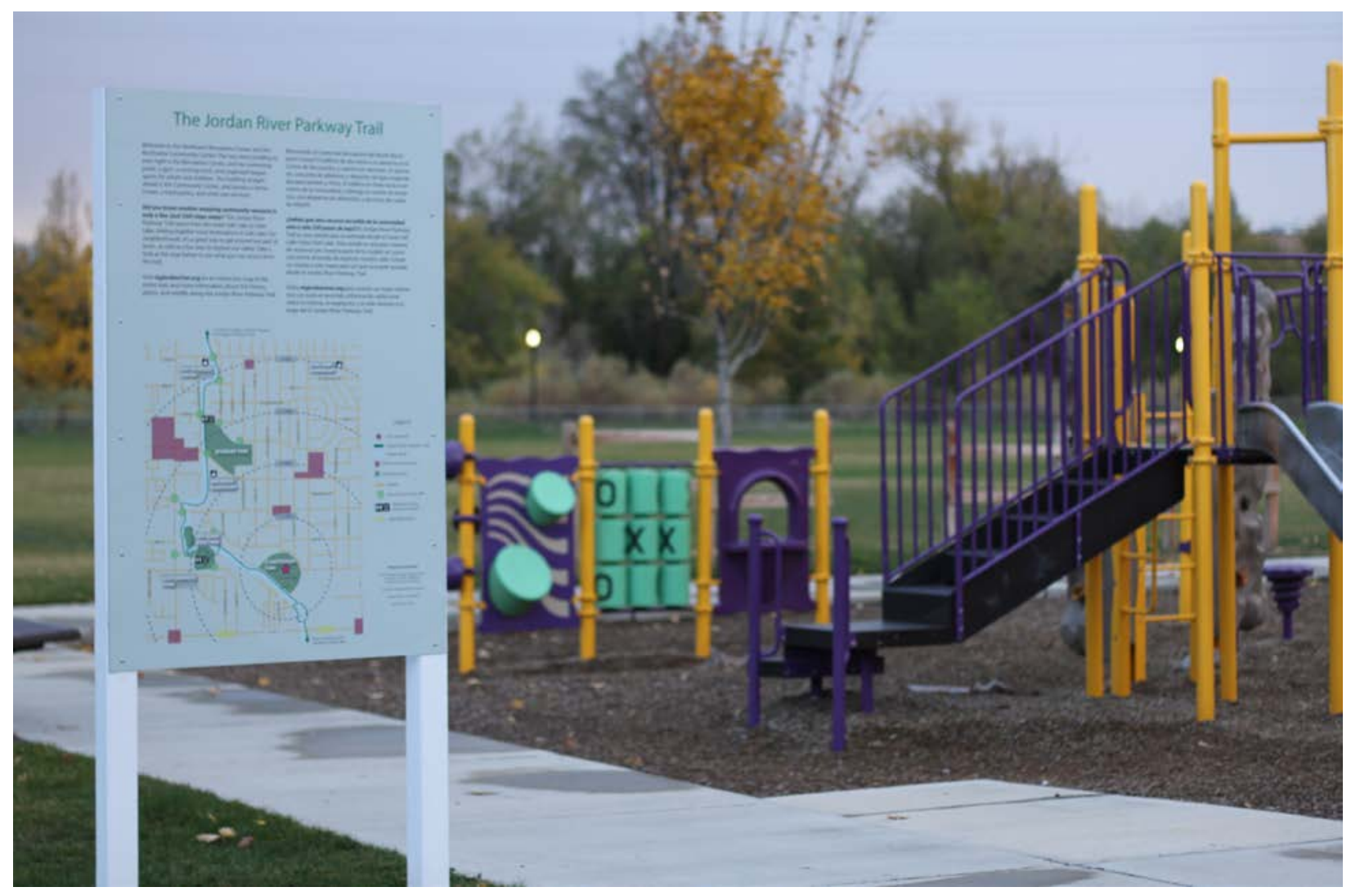

Figure 5. Sign designed and installed by Westside Studio to raise awareness of destinations.

\subsection{PEDESTRIAN ENGAGMENT AND PUBLIC ART}

The lack of pedestrian engagement was one of the issues that people raised in the focus group discussion, so we Westside Studio students also engaged in a mural revitalization project with NeighborWorks, a community development corporation that has been encouraging businesses to fix their facades. The focus was a mural at 800 West North Temple in a vacant building. In an effort to assist with positive neighborhood branding, students and NeighborWorks partnered with local mural artist Zach Franzoni to paint a mural that reads, the North Temple District of the NOTE District in an effort to make the area a place. Future classes might study public art in Salt Lake City, including its role in community building and branding and develop plans to further emphasize and support active transportation in the area. We are happy to report that a month after students painted the mural, the owner of the building was able to lease it after being over a year vacant. Thus, beautifying a place, even at a very low-cost budget, could also be a way to attract new business into the area. 


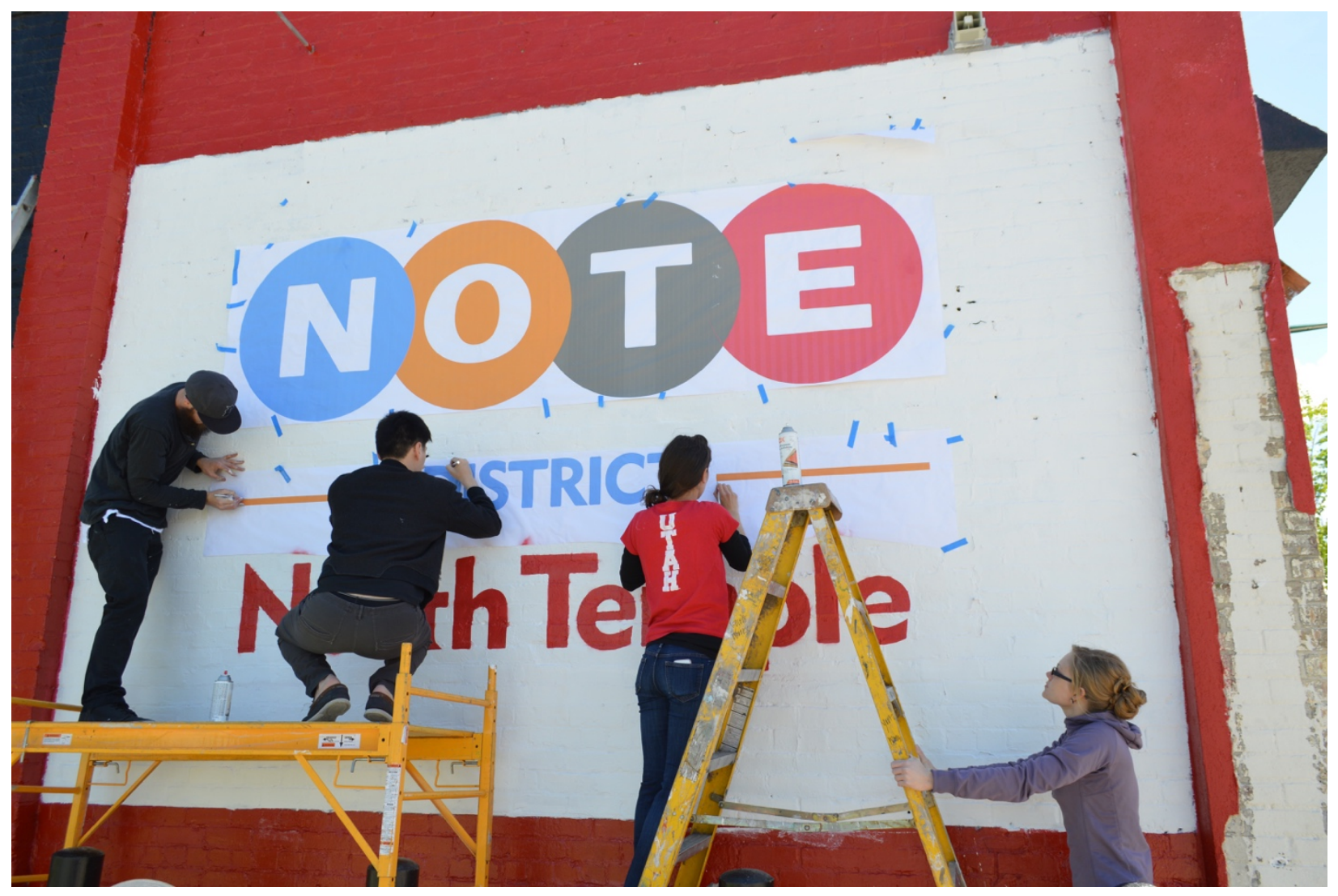

Figure 6: Mural on North Temple being restored by Westside Studio students and partners. 


\subsection{CONCLUSION}

The west side neighborhood of Salt Lake City is a diverse and unique area and a valuable part of the city. Westside Studio set out to examine one of the neighborhood's major assets, the Jordan River Parkway Trail and to study the connectivity between the trail and North Temple, an important arterial road connecting the west side to downtown, with the goal of promoting active transportation options. Research was conducted using quantitative and qualitative methods, including secondary data analysis, focus groups and surveys and on site assessments of neighborhood assets.

Fewer individuals were found to take advantage of the community assets - the Jordan River Parkway Trail and the North Temple corridor, even when they lived 1 mile and 1.5 miles at the most. About one third of those who use the trail used other destinations in the neighborhood, including North Temple. However, many residents were not even aware of the existence of the trail and hardly engaged in active transportation. The data from the focus group and the user surveys suggest that although streetscape improvements enhanced the neighborhood aesthetics and increased accessibility somewhat along North Temple, it is not enough to serve the broader purposes of attracting most people to walk, bike or take transit in the area. If safety interventions are not embedded in the community's design and social fabric, it will fail to bring in the desired sense of place. While access to the light rail station and amenities, specifically, groceries and restaurants were viewed positively, homelessness and the inadequacy of safety after dark mattered highly to residents.

To go back to the objectives of the study, and broaden up, from our case study, it is important to note that Transit Oriented Development (TOD) — in particular light rail with residential and commercial spaces - is often considered one of the most reliable strategies in the tool box of planners and other decision makers that affect the build environment to encourage transit and active transportation modes such as walking and biking. Nonetheless, the efforts from policy makers to reduce dependence in automobile do not tend to take into account the presence of trails near TOD and how they might affect each other. Perhaps, one of the reasons why these connections are not made is because trails are associated with particular modes of leisure that is, walking and biking for the sake of walking and biking as opposed to accessing retail, schools, and community centers through the trail in order to avoid traffic and increase pleasurability.

We found in this Salt Lake City case study, and we think that this might be true for other cities across the nation, that people use the trail for many purposes (e.g. shopping, taking their kids to school to mention a few). Some even use it to get to the TOD zone to access transit, restaurants, shopping and so on. However, connections between TOD areas and trails are not made obvious. More often than not, transit investments in most cities are aimed at carved out TOD zones where planners feel that they can have an impact through a pre-determined design and development patterns that developers and the market could easily follow. The concern is less on the overall connectivity of a neighborhood, which might include trails in proximity to TOD, because these might be outside of the TOD boundaries.

We hope that people from other cities found in our case study useful we found. For example, we found that by adding signage and improving a sense of security the quality of these neighborhoods policy makers can enhance and even have the possibility of attracting new users; 
those residents who do not know where the trail is or the TOD zone in the neighborhood, but also those coming from outside of the neighborhood, like bikers and runners who might arrive by light rail to use the trail. Like Salt Lake City's west side, many low-income neighborhoods have great amenities_-like TOD and trails_-but they might not be perceived as amenities because of the sense of insecurity. In other words, many other disadvantaged neighborhoods, where there are relatively good places to walk are perceived as places that one should not walk alone, in the dark and so on.

Even if there are massive public investments in large infrastructure like TOD, low-income neighborhoods struggle to add commercial destinations that encourage walking such as cafes, restaurants, and the like. While a lot of the transportation related public policy is around creating TOD to provide transit in low-income areas, the economic development piece, although acknowledged to a great extent, still missing. Fortunately, TOD advocacy has been successful in bringing transit to many low-income areas. Thus, a growing number of communities today do not experience the lack of public transportation they experienced decades ago. TOD developments are really helping to close this gap. However, social exclusion is manifested in other ways. For example, there still a lack of services in low-income neighborhoods which is combined with perception of the lack of safety. Although communities might be transit rich, active transportation and transit ridership is affected by a multitude of factors including land use patters, density, mixed-uses and so on. Creating a transit-rich and amenity-rich neighborhood in low-income areas without creating displacement is change that would not be easily overcome.

Finally, the trends we have identified in this study, can generally apply to many neighborhoods where there is TOD and trails. This research has demonstrated that the success encouraging the use of transit, walking, and biking will depend in increasing the perception of safety, improving signage that shows where destinations are and finally adding destinations in walkable and bikeable areas with access to transit. in the TOD area as well as near trails. We hope that recommendations from this report can be used as building blocks for future projects and for additional studies on interventions that can benefit residents in low-income areas. These kinds of projects should be a positive step in bridging the TOD areas with trails and in better integrating districts, neighborhoods and cities. 


\subsection{REFERENCES}

Adams, Brooke. “Church Methodist Tongan united.” The Salt Lake Tribune. July 23, 2013. Accessed February 16, 2016. www.sltrib.com/sltrib/news/56627086-78/church-methodisttongan-united.html.csp.

Alfonzo, M., 2005. To walk or not to walk? The hierarchy of walking needs. Environment and Behavior, 37, 808-836.

Bargh, J., and Chartrand T. 1999. The unbearable automaticity of being. Am Psychol; 54:46279.

Bargh, J., Ferguson M. 2000. Beyond behaviorism: on the automaticity of mental processes. Psychol Bull; 126:925-45.

Bauman, B., and Pakpour, J. 2004. Sidewalk and streetscape improvement project revitalizing historic downtown Hayward. American Public Works Associaiton; https://www.apwa.net/Resources/Reporter/Articles/2004/9/Sidewalk-and-streetscapeimprovement-project-revitalizing-historic-downtown-Hayward

Beidler, K. J., 2007. Sense of Place and New Urbanism: Towards a Holistic Understanding of Place and Form. Ann Arbor, MI.

Boren, Ray “Now \& Then-A Time Traveler’s Guide to My Old Neighborhood.” Mapping SLC. 10 Feb 2016. www.mappingslc.org/this-was-here/item/121-.

Briggs, Xavier de Souza. "Doing Democracy Up-Close: Culture, Power and Communication in Community Building.” Journal of Planning Education and Research 18, no. 1 (September 1, 1998): 1-13.

Brooke, A. July 23, 2013. "Utah Local News Salt Lake City News, Sports, Archive The Salt Lake Tribune." Utah Local News Salt Lake City News, Sports, Archive. The Salt Lake Tribune. Accessed February 16, 2016. www.sltrib.com/sltrib/news/5662708678/churchmethodisttonganunited.html.csp

Brown, Barbara B., Carol M. Werner, Calvin P. Tribby, Harvey J. Miller and Ken R. Smith. “Transit Use, Physical Activity and Body Mass Index Changes: Objective Measures Associated With Complete Street Light-Rail Construction.” American Journal of Public Health 105, no. 7 (July 2015): 1468-74.

Calthorpe, Peter. 1995. The Next American Metropolis: Ecology, Community and the American Dream. 3rd edition. New York: Princeton Architectural Press.

Carter, Ben. “Segregating Sanitation in Salt Lake City, 1870-1915.” Utah Historical Quarterly. 82.2 (2014):92-113. 11 Feb 2016.

Christina M., Thornton, T. L., Conway, K. L., Cain, K. A., Gavand, B. E., Saelens, Lawrence D. F., Carrie M. G., Karen G., Abby C. K., James F. S. 2016. Disparities in pedestrian streetscape environments by income and race/ethnicity, SSM - Population Health; 23528273, 
Clifford, B. (2016, February 16). Salt Lake City Neighborhoods. Retrieved April 07, 2016, from http://www.cityweekly.net/utah/salt-lake-city-neighborhoods/Content?oid=2160273

Daley, John. “Airport TRAX line to revamp North Temple.” www.ksl.com/?nid=148\&sid=5870032.

Davidson, Lee. “Study: UTA Rail Projects Helped Fuel Economic Growth.” The Salt Lake Tribune. June 29, 2015. Accessed April 27, 2016. www.sltrib.com/home/2665260-155/ study-uta-rail-projects-helped-fuel.

E. Lora, A. Powell et al. 2010. The Quality of Life in Latin American Cities, Markets and Perception, The Inter-American Development Bank, Washington, United States.

Emond, Catherine, Wei Tang and Susan Handy. 2009. "Explaining Gender Difference in Bicycling Behavior.” Transportation Research Record: Journal of the Transportation Research Board 2125 (November): 16-25. doi:10.3141/2125-03.

Ewing et al. Growing Cooler: The Evidence on Urban Development and Climate Change, Urban Land Institute, Washington, D.C., 2007, Chapter 4 (pp. 65-71, 83-89.

Ewing, Reid and Robert Cervero. 2016. "Travel and the Built Environment - Journal of the American Planning Association - Volume 76, Issue 3.”

Ewing, Reid and Susan Handy. "Measuring the Unmeasurable: Urban Design Qualities Related to Walkability.” Journal of Urban Design 14, no. 1 (February 1, 2009): 65-84.

Field MJ and Jette AM, "FirstMed Locations", Institute of Medicine (US) Committee on Disability in America, 2007, National Academy of Sciences. Accessed February 16, 2016. www. rstmedclinic.com/locations.html.

Gaber, John. “Chapter 3: Photographic Research.” In Qualitative Analysis for Planning \& Policy: Beyond the Numbers, 1 edition. Chicago, IL: APA Planners Press, 2007.

Hallaran, Kevin. 2016. “Utah History Encyclopedia.” Accessed August 1. http://www.uen.org/utah_history_encyclopedia/j/JORDAN_RIVER.html.

Handy, S. L.,, Boarnet, M. G., Ewing, R. and Killingsworth, R. E. 2002. How the built environment affects physical activity: Views from urban planning, American Journal of Preventive Medicine; 23 (2) : 64-73

Handy, S. Understanding the link between the built environment and nonwork travel behavior. J Planning Educ Res, 15 (1996), pp. 183-198

Heesch, Kristiann C., Billie Giles-Corti and Gavin Turrell. “Cycling for Transport and Recreation: Associations with Socio-Economic Position, Environmental Perceptions and Psychological Disposition.” Preventive Medicine 63 (June 2014): 29-35.

Hemingway, S.; White, J.; Turner, J.; Dewhirst, K.; Smith, G. 2012. The Medicine with Respect Project: A stakeholder focus group evaluation. Nurse Educ. Pract; 12: 310-315.

Hoagland, A. K. 1985. Department of the Interior. National Park Service. Nelson Wheeler Whipple House. Accessed 11 Feb 2016.

Hoagland, Alison. Department of the Interior. National Park Service. Nelson Wheeler Whipple House. 1985. Web 11 Feb 2016. 
Jacobs, Jane. 1961. The death and life of great American cities. New York: Vintage Books.

Jensen, Derek. “Glendale Library Saga Nears Final Chapter.” The Salt Lake Tribune. December 29, 2010. Accessed February 16, 2016. archive.sltrib.com/story.php?ref=/sltrib/ home/50865845-76/library-glendale-river-west.html.csp.

Keefe, John, Steven Melendez and Louise Ma. "Commute Times in Your Area | WNYC.” Average Commute Times. Accessed February 17, 2016. project.wnyc.org/commute- mesus/embed.html\#12.00/40.8072/-111.9546.

Kienteka, Marilson, Cassiano Ricardo Rech, Rogério César Fermino and Rodrigo Siqueira Reis. "Validity and Reliability of an Instrument to Measure Barriers to Bike Use in Adults." Revista Brasileira de Cineantropometria \&amp; Desempenho Humano 14, no. 6 (December 2012): 624-35.

King, A. C.,Jeffery,R. W.,Fridinger,F.,Dusenbury,L., Provence,S.,Hedlund,S. A.,\& Spangler,K. 1995. Environmental and policy approaches to cardiovascular disease prevention through physical activity: Issues and opportunities. Health Education Quarterly, 22(4), 499-511.

Kitzinger, J. 1994. The methodology of Focus Groups: The importance of interaction between research participants. Sociol. Health Illn; 16: 104-121.

Kiyotaka, F. and Yoichi, K. 2003. The role of design elements on the cost-effectiveness of streetscape improvement, Landscape and Urban Planning; 63 (2): 75-91

Kloosterman, Robert C. and Trip, Jan Jacob. 2011. Planning for Quality? Assessing the Role of Quality of Place in Current Dutch Planning Practice. Journal of Urban Design; 16 (4): 455470.

Kockelman et. al. "Meeting the Intent of ADA in Sidewalk Cross-Slope Design.” Journal of Rehabilitation Research and Development 38 (1):101-110, 2001.

Kretzmann, John P. and John L. McKnight. "Introduction.” In Building Communities from the Inside Out: A Path Toward Finding and Mobilizing a Community’s Assets, 1 edition. Evanston, Ill.; Chicago, IL: ACTA Publications, 1993.

Ladd, B.K. 1987. Urban aesthetics and the discovery of the urban fabric in turn-of-the-century Germany. Planning Perspectives, 2: 270-286

Laine, Mike. UtahRails.net. Accessed April 27, 2016. utahrails.net/streetcars/lainestreetcars.php.

Lamb, Michael E. The father’s role: Cross cultural perspectives. Routledge, 2013.

Litvin, S. W. 2005. Streetscape improvements in an historic tourist city a second visit to King Street, Charleston, South Carolina, Tourism Management, 26 (3): 421-429.

Macintyre, S., Maciver, S., and Sooman, A. 1993. Area, class and health: Should we be focusing on places or people? Journal of Social Policy; 22(2): 213-234.

Madina, Masjid. Sharery.blogspot, September 14, 2013. Accessed February 14, 2016. sharery.blogspot.com/2013/09/madina-masjid-di- salt-lake-city-utah.html. 
Mattson et. al. 2014. "Evaluating The State Of Mobility Management And Human Service Transportation Coordination.” http://www.nctr.usf.edu/wpcontent/uploads/2015/08/77060_NCTR_NDSU05.pdf.

McCrea, R., Stimson, R.., and Western, J. 2005. Testing a moderated model of satisfaction with urban living using data for Brisbane-South East Queensland, Soc. Indic. Res. 72: 121-152.

McLeroy, K. R., Bibeau, D., Steckler, A., and Glanz, K. 1988. An ecological perspective on health promotion programs. Health Educ Behav; 15: 351-377.

Mitchell, Chip. "Real-Estate Developer in Hot Area Sees Bright Future and Displacement.” WBEZ, December 15, 2015. http://www.wbez.org/.

Monsere, Chris. 2014. "Lessons From The Green Lanes: Evaluating Protected Bike Lanes In The U.S.” National Institute for Transportation and Communities (NITC). http://bikeportland.org/wp-content/uploads/2014/06/NITC-RR583_ProtectedLanes_FinalReportb.pdf.

Morgan, D.L. 1996. Focus Groups. Annu. Rev. Social; 22, 129-152.

Myers. Dowell. 1988. Building Knowledge about Quality of Life for Urban Planning, Journal of the American Planning Association, 54:3, 347-358

Newman, Oscar. 1972. Defensible space: crime prevention through urban design. New York: Macmillan

P.M. Hess. 1997. Measures of connectivity. Places, 11 (1997): 58-65

Passel, Jeffrey S., D’Vera Cohn and Mark Hugo Lopez. "Hispanics Account for More than Half of Nation's Growth in Past Decade.” Pew Research Center's Hispanic Trends Project. Accessed December 1, 2015. http://www.pewhispanic.org/2011/03/24/hispanics-accountfor-more-than-half-of-nations-growth-in-past-decade/.

Rountree, P. W. and Land, K. C. 1996. Perceived risk versus fear of crime: empirical evidence of conceptually distinct reactions in survey data. Soc Forces; 74(4):1353-1376.

Rowley, A. 1998. Private-property decision makers and the quality of urban design, Journal of Urban Design, 3(2): 151-173

Saelens B, Sallis JF, Frank L. 2003. Environmental correlates of walking and cycling: findings from the transportation, urban design, and planning literatures. Ann Behav Med; 25:80-91.

Sallis JF, Bauman A, Pratt M. 1998. Environmental and policy interventions to promote physical activity. Am J Prev Med; 15:379-397.

Salmon J, Owen N, Crawford D, Bauman A, Sallis JF. 2003. Physical activity and sedentary behavior: a population-based study of barriers, enjoyment, and preferences. Health Psychol; 22:178-88.

Salt Lake City Northwest Historic District. Gombach Group, last modified 2011. Date accessed February 13, 2016.

http://www.livingplaces.com/UT/Salt_Lake_County/Salt_Lake_City/Salt_Lake_City_North west_Historic_District.html 
Sauter, D., \& Huettenmoser, M. 2008. Liveable streets and social inclusion. Urban Design International, 13 (2), 67-79.

Scott, A. 2011. Focussing in on focus groups: Effective participative tools or cheap fixes for land use policy? Land Use Policy, 28, 684-694.

Skogan WG: 1987. The impact of victimization on fear. Crime Delinq, 33(1):135-154.

Skop, E. 2006. The Methodological Potential of Focus Groups in Population Geography. Popul. Space Place; 12, 113-124

Social Explorer U.S. Census Bureau. ACS 2013 (5-Year Estimates) (SE), ACS 2013 (5-Year Estimtes). Social Explorer. 2015. Accessed February 17, 2016. www.socialexplorer.com/ tables/ACS2013_5yr/R1111971.

Southworth, M., 2005. Designing the walkable city. Journal of Urban Planning and Development, 131, 246-257

Stephenson, Gordon. 1992. On a Human Scale: A Life in City Design. South Fremantle, W.A: Fremantle Arts Center Pr.

Strack, Don. 2016. “Railroads in Utah.” Accessed April 27. http://historytogo.utah.gov/utah_chapters/mining_and_railroads/railroadsinutah.html.

Thompson, Amy. "National Register of Historic Places Nomination on: Twenty-Ninth Ward House, 1102 W 400 North.” Salt Lake City Planning Division. 4 Dec 2014. www.slcdocs.com/ Planning/HLC/2014/29.pdf.

U.S. Census Bureau. 2016. “American FactFinder.” Accessed August 1. http://factfinder.census.gov/faces/nav/jsf/pages/index.xhtml.

U.S. Census Bureau. Types of Health Insurance Coverage by Age.” American FactFinder. 2015. Accessed February 15, 2016. factfinder.census.gov/faces/tableservices/jsf/pages/productview. xhtml?pid=ACS_13_5YR_B27010\&prodType=table.

University Neighborhood Partnership Area. (n.d.). Retrieved April 22, 2016, from http://partners.utah.edu/neighborhoods/westside-neighborhood-profile/

UTA. “Art Along the Airport TRAX Line.” www.rideuta.com/news/2013/04/art-along-theairport-trax-line

Vikas, M. 2008. Walkable streets: pedestrian behavior, perceptions and attitudes, Journal of Urbanism: International Research on Placemaking and Urban Sustainability, 1:3, 217-245.

White, John G., Antos, Mark J., Fitzsimons James A., Palmer Grant C. 2005. Non-uniform bird assemblages in urban environments: the influence of streetscape vegetation, Landscape and Urban Planning, 71 (2-4) : 123-135.

Willis, K.G, Garrod G.D, Harvey D.R. 1998. A review of cost-benefit analysis as applied to the evaluation of new road proposals in the UK. Transport. Res. D, 3 (3): 141-156.

- “Chapter 4: Focus Group Research.” In Qualitative Analysis for Planning \& Policy: Beyond the Numbers, 1 edition. Chicago, IL: APA Planners Press, 2007. 
“Chapman.” Salt Lake City Public Library. Accessed February 16, 2016. www.slcpl.org/branches/view/Chapman.

“Cottonwood Park.” Parks. Accessed February 16, 2016. www.slcgov.com/cityparks/parkscottonwood-park.

“Habitat for Humanity”. Accessed February 15, 2016. www.habitatsaltlake.com.

“Jordan River Parkway Trail.” www.bikeslc.com/jordanrivertrail/default.html.

“Map of Salt Lake City Showing Street Car Routes.” Electric Railway Journal. 1921. 13 Feb 2016. vodaplan.com/wp-content/uploads/2011/02/Salt-Lake-City-Streetcar-Map-1921. jpg.

“Marmalade.” Salt Lake City Public Library. Accessed February 16, 2016. www.slcpl.org/branches/view/Marmalade.

"Neighborhood House”. Accessed February 15, 2016. nhutah.org.

“Northwest Recreation Center.” Salt Lake County. Accessed February 16, 2016. www.slco.org/recrea on/northwest.

“Riverside.” Salt Lake City Public Library. Accessed February 16, 2016. www.slcpl.lib.ut.us/branches/view/Day-Riverside.

“Salt Lake City Northwest Historic District.” Gombach Group, last modified 2011. Date accessed February 13, 2016.

"Salt Lake City Northwest Historic District”, Salt Lake City, Salt Lake County, Salt Lake City, UT, 84116. Accessed April 27, 2016. www.livingplaces.com/UT/Salt_Lake_County/ Salt_Lake_City/Salt_Lake_City_Northwest_Historic_District.html.

“Salt Lake Community Action Program”. Accessed February 13, 2016. www.slcap.org.

“Salt Lake County Parks.” Constitution Park- Salt Lake County. Accessed February 16, 2016. www.parks.slco.org/constitution/index.html.

"Social Determinants of Health.” Healthy People. Accessed February 15, 2016. www.healthypeople.gov/2020/topics-objec ves/topic/social-determinants-of-health.

“Together We Can Make a Difference, Not Just for One Day but a Life Time!” Salt Lake City Mission, Charity Service, Donate, Give, Volunteer, Fund Raising, Food Drive, Homeless, Salt Lake, UT. Accessed February 15, 2016. saltlakecitymission.org.

“Transit Amenities”, Indygo, accessed February 17th 2016 www.indygo.net/aboutindygo/transit-amenities.

"Transit shelters and other amenities affect perceived wait times", accessed February 17th 2016, www.cts.umn.edu/publications/catalyst/2015/january/transit.

"Upcoming Events.” Utah State Fair Park-. Accessed February 16, 2016. www.utahstatefairpark.com/events.

“US Demography 1790 to Present.” Social Explorer. 2015. Accessed February 17, 2016. www.socialexplorer.com/6f4cdab7a0/explore.

"Utah Association of Fairs and Events." Utah Association of Fairs and Events. Accessed February 15, 2016. www.utahfairsandevents.org. 
"Utah Friends of Paleontology Home.” Utah Friends of Paleontology Home. Accessed February 15, 2016. www.utahpaleo.org.

“Utah Motorsports Foundation.” Organization Report. Accessed February 15, 2016. www.guidestar.org/profile/87-0628481.

“Utah State Legislature.” Utah Legislature. Accessed February 16, 2016. le.utah.gov/Interim/2001/committeelinks/detailedschool.htm.

“Westside Studio.” University Neighborhood Partners. partners.utah.edu/partnerships/community-capacity-building/westside-studio. 
Transportation Research and Education Center

Portland State University

1900 S.W. Fourth Ave., Suite 175

Portland, OR 97201 